\title{
Simulation of a PWR power plant for process control and diagnosis
}

Nielsen, F.R.

Publication date:

1991

Document Version

Publisher's PDF, also known as Version of record

Link back to DTU Orbit

Citation $(A P A)$ :

Nielsen, F. R. (1991). Simulation of a PWR power plant for process control and diagnosis. Risø National Laboratory. Denmark. Forskningscenter Risoe. Risoe-R No. 609(EN)

\section{General rights}

Copyright and moral rights for the publications made accessible in the public portal are retained by the authors and/or other copyright owners and it is a condition of accessing publications that users recognise and abide by the legal requirements associated with these rights.

- Users may download and print one copy of any publication from the public portal for the purpose of private study or research.

- You may not further distribute the material or use it for any profit-making activity or commercial gain

- You may freely distribute the URL identifying the publication in the public portal

If you believe that this document breaches copyright please contact us providing details, and we will remove access to the work immediately and investigate your claim 


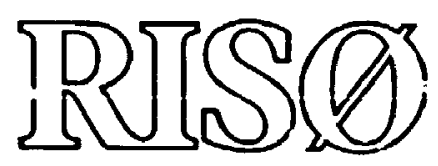

\section{Simulation of a PWR Power Plant for Process Control and Diagnosis}

Finn Ravnsbjerg Nielsen

Ris $\varnothing$ National Laboratory, Roskilde, Denmark December 1991 


\section{Simulation of a PWR Power Plant Risa-R609(EN) for Process Control and Diagnosis}

Finn Ravnsbjerg Nielsen

Ris $\emptyset$ National Laboratory, Roskilde, Denmark December 1991 
Abstract. A computer model of a simplified pressurized nuclear power plant is developed with aim at studies conceming process control, diagnosis and decision making.

The model includes the traditional PWR plant components. primany circuit with reactor. pressurizer and steam generator. steam circuit with steam line, turbine and condenser. intciconnected with punps. valves and controllers. The model can be used for calculation of transients for both normal operation and incidents such as turbine trip. loss of feedwater. nun down of pumps or various valve failures.

The computer model is not directed to any specific existing plant. For convenience and alleviation in implementation the physical desciption of many components are simplified to an extent where the qualitative behavior of the system is not violated. For computer memor: economy a varisty of thermodynamical functions for water and sicam have been approximated with analytical expressions base on table values.

The model is implemented in the Clanguage and has been nun on both the IBM PC and the SUN workstation.

Riso National Laboratory

Cognitive Systems Group

P.O.Box 49

DK-4000 Roskilde. Denmark

ISBN 87-550-1767-3

ISSN 0106-2840

Grafisk Service, Risøo 1991 


\section{Contents}

1 Introduction 5

2 System description 5

2.1 Nomenclature and component list 6

2.2 Thermodynamical functions 7

3 System modeling 9

3.1 Main units representation 10

3.2 Control system representation 21

3.3 Plant componeme interaction 25

3.4 Malfunction and operator conkrol capabilities 31

3.5 Physical alarms 33

5.6 Interlock and safety sysiems 33

4 References 34

A Neutron dynamics and reactor effect 35

B Two-phase mixture calculation 36

C Numerical integration stratezy 38

D Thermodynamical approximations 40

E Power plant process variables 43

F Model steady state input data 49 


\section{Introduction}

This repor describes a comput: simulation of a simplified pressurized nuclear power plant model direcled towards process control diagrinsis ark' decision making.

The physical power plant modei is intended to be integrated into a real time data base managerient system, where the physical prociss simulation should be monitored concurrently with a number of tasks such as operator input. 'formation cisplay. limit checking activity, data recording and malfunction handling.

The mocel is an enlargemeis of a previus model used for studies of operator activities (Hojberg.1982) as some changes have ieen peringmed conceming functional structure and complexity. New components have been added $(t)$ the nodel ard the numerical strategies used for solving the state variable difterential equations have seen modif $\mathrm{e}$.

\section{System description}

The power plant model is depicted in figure 1. It includes all basic PWR componcnts as lumped elements inte, connected by ideal frictionless pipes. T?:e PWR power plant is a $856 \mathrm{MW}$ single loop heat transport system with a vertical (I-tube natural recirculation type steam generator and a single primary pump. A pressurizer is located on the hot reactor leg and a volume control system is connected !o the cold leg. The reaclor is simulated as a very simplified one-dimensional nuclear system without reactivity feedback mechanisms, coolant borcn i oncentration systems or possibility of steam production and void formation. The power generated is controlled by a single control rod regulated by a s:mple rod drive mechanism.

The single steam line cornects the steam generator with a turbogenerator system consisting of a single high pressure turbine driving a $30 \mathrm{KV}$ electric gererator. The feedwater system consists of a condenser connected to the steam generator via a single p:ımip. A single bypass valve is available for steam dump directly to the condenser and safety valves are present for both the pressurizer and steam line system.

No attempt is made to include moisture separation or preheater systems. Moreover the model includes lubrication systems with filter components for the reactor coolant pump and the feedwater pump.

Six mair contro! system: are incorporated in the modal - control of reactor power by regulation of control rod position, contrel of primary pressure by reguiation of spray valve cooling flow or pressurizer heating. control of water level in the pressurizer ty regulation of letdown and charging coolant flows, control of steam line pressure by regulation of reactor power demand, control of water level in the steam generator by regulation of feedwater puinp flow and control of generator voltage by regulation of turbine vaive pusition.

The model can be used for - ilculating transients for both r.umal and abnomal occurences with only few limitations. Ir, the primary cuoiant system two-phase flow is not allowed and pressurizer and steam generator volumes may not tre einptied or overfilled. Pressures should be within the range from 0.01 bar to 200 bar and temperatures in th: range from 10 to 350 Celcius degree. Under these wide conditions severe transients may me simulated such as loss of cooling accidents, loss of load, loss of feedwater or failure in varinus va!ves, pumps and controllers.

All pumps, control valves and controllers in the model operate in either auto/nnanual or failed mode. and all pumps, valves and controiler components are thus prepared for malfunction accidents. 


\subsection{Nomenclature and component list}

The plant model components are identified a single numbers with reference to figure 1 and listed in the following table

Table I. Plant model components

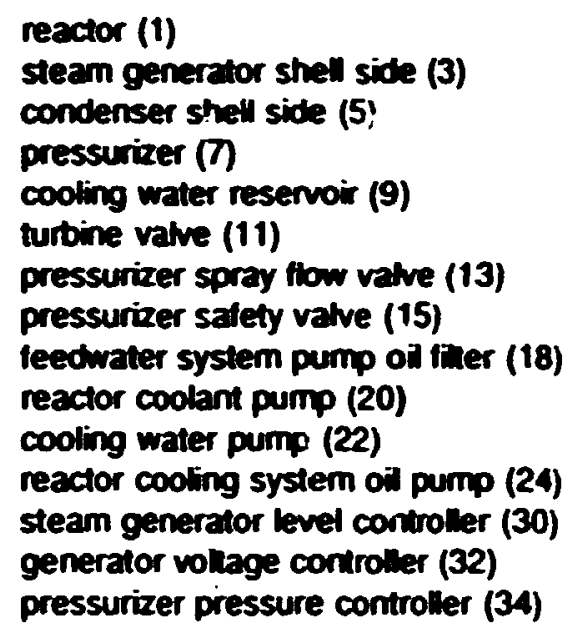

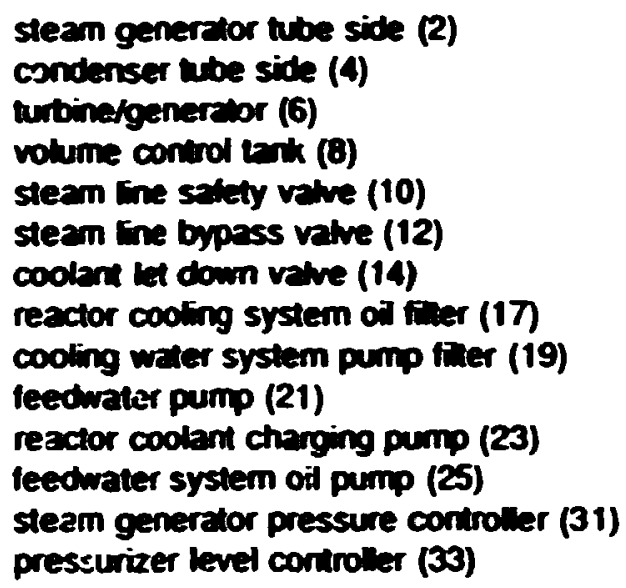

Physical process variables used in the power plant simulation are listed in appendix A and grouped in state variables. parameters and constants. All process variables are identified by short symbols indexed by a number refering to the def'ning physical component (figure 1). Process variable symbols used in this repon appears in the same tont as used in table 1. 


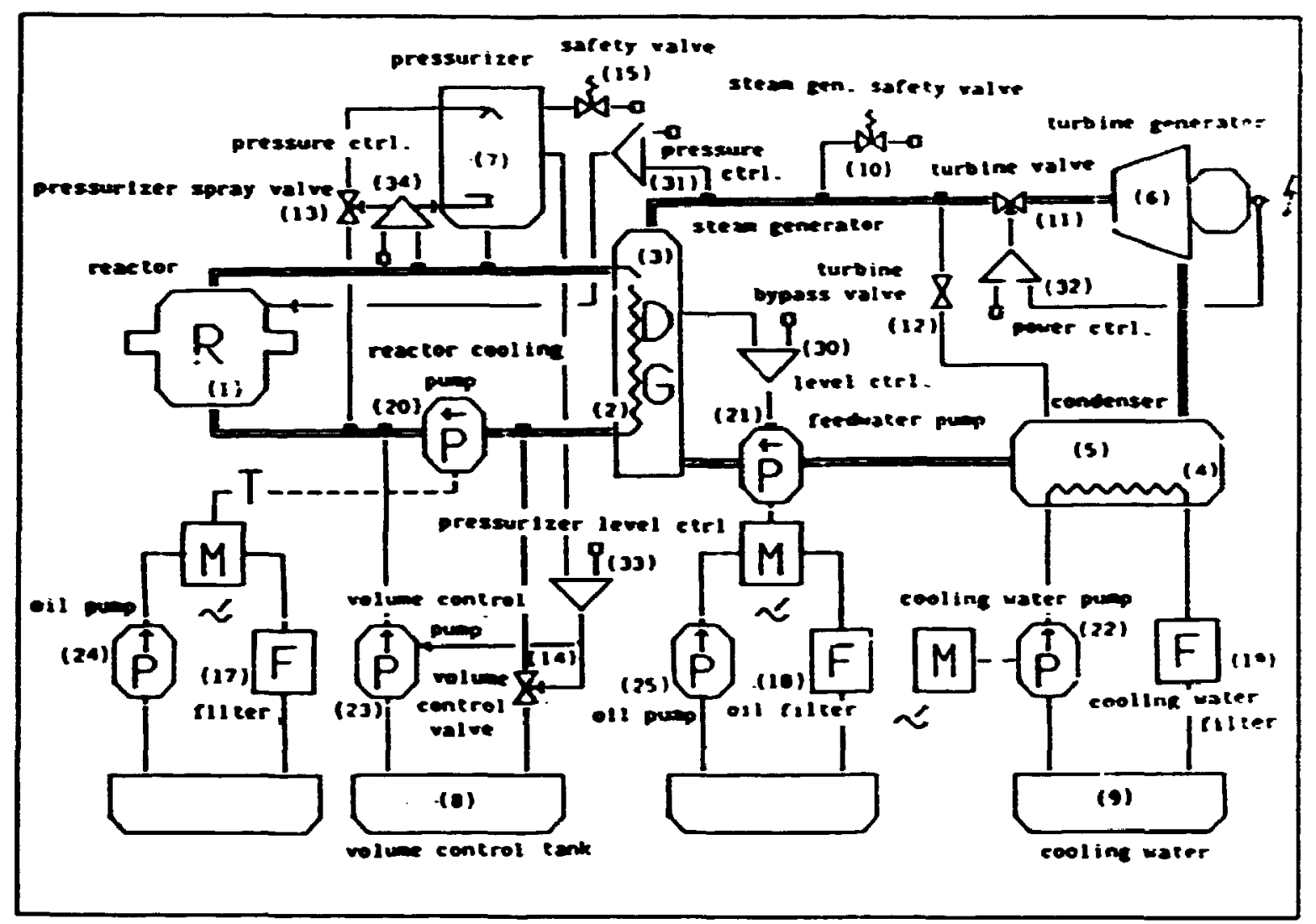

Figure 1. The PWR Power Plant

\subsection{Thermodynamical functions}

In the computer simulation the accurae calculation of a variety of thermodynamical functions for water and stean plays a significant role for the reliability of the model.

The thermodynamical functions used in the plant model are summarized in Table 2.

The argument $P$ denotes pressure in bar, $T$ tempernoure in Celcius degree and u specific energy $\mathbf{M J / K g}$. 
Table 2 - Thermatronamical funcrions

\begin{tabular}{|c|c|c|}
\hline$\rho(I)$ & densily of wher (ussauraced) & Ketma' \\
\hline$\rho d P$ & density of somuried wzer & $\mathrm{Ke} / \mathrm{wa}^{2}$ \\
\hline$P(P)$ & dessily of sabureted stesm & Ketm: \\
\hline$n(1)$ & enthalyy of waser (unsonureved) & $\mathbf{M} / \mathbf{K}_{\mathbf{8}}$ \\
\hline$n_{n}(n)$ & enthalp: of sowred waer & $M / K_{8}$ \\
\hline$m_{d}(A)$ & entha'py of setureded stem & $M J / K_{8}$ \\
\hline$s_{x}(P)$ & entropy of sotureded water & $\mathbf{M} / \mathbf{K}_{\mathbf{Z}}$ \\
\hline$s(P)$ & entropy of setureded seen & $M / K_{g}$ \\
\hline$T_{s}(P)$ & lemperanure of soturied seem & $\propto$ \\
\hline$T_{d}(u)$ & iemperature of weter (unsomurated) & $\infty C$ \\
\hline$\frac{d}{c} \rho d(\lambda)$ & wacer densily gradien & $\mathrm{Kg} / \mathrm{m}^{3} / \mathrm{oc}$ \\
\hline
\end{tabular}

Table values for all seem and waer functions, except densily of water. are found in (Wasserdampfrafeln.1963) and have to be approximated by analytical expressions due to compuer memory limitation. Common to all these strong non-linear functions is that they all refuse polynomial approximation of modest order through the relative wide range needed for pressure (from 0.01 bar to aboul 200 bar) and for temperanure (from 10 to aboul 350 Celcius degree). if an accuracy betuer than 1 per cen should be achieved. The approximation method used is to split the functions over appoppriate subimervals and fit the funcions piece by prece by either polynomials or rational functions of modest degree.

The approximations from table values were calculated by a standard library algorium (Wiese.1969). which performs the approximations using the Chebyshev norm for minimizing the maximal relative derivation from the exact table values. The approximation resuls are tabulated in appendix $\mathbf{E}$.

The enthalpy function $h_{d}(\eta)$ and the kemperaure function $T_{-}(U)$ are applied for unsaturated primary coolant water. and hence the functions should be pressure dependerm. However. iwo-argument analytical approximations is avoided. and as the pressure dependency is of minor imponance compared to temperature dependency. a compromise is performed approximating the functions for fixed high pressure ( 150 bar).

The density function $P_{\mathrm{w}}(\boldsymbol{\eta})$ is calculated by use of an expression derived from a formula quoted in iKeeman \& Keyes.1948). This formula originally contains both pressure and temperature arguments. but the pressure dependency is omitued due to its minor significance.

The approximation used in the model is

$$
P_{d}(n)=\frac{1000.0}{3.083-0.8090\left(374.1-n^{0.10017}\right.} \quad \mathrm{Kom} \mathrm{m}^{3}
$$




\section{System modeling}

The thermal dynamic models for the plant components are lunped peraneter descriptions imen on basic physical equations. and the plan model is described by mass and energy conservation laws. The plan moded is not directed to any specific existine plane and bence the physical description of all components are simplified to an extent where the qualibative behavior of the system is not viol. ed. In generd this is done by linearizations which mates computing faster and simplifies involved impicit alaebraic strucures and their andyical solution. Verifications by companison of urasients from simblars simulating similiar models of the PWR type has not been made as many of the dat used are ondy provisional. Available data is adapted from a Westingtouse PWR power plant.

The anathematical detsils of the plan component description are oultined in (Lind.1982). In the following sections the actual mathematical equations used are gaoted with figures. and paranesizen mubers refer to these equations.

The model is implemented in the C language and has been ron on both IBM PC and the SUN worketation. 


\subsection{Maia units representation}

\subsubsection{Reacear nodet}

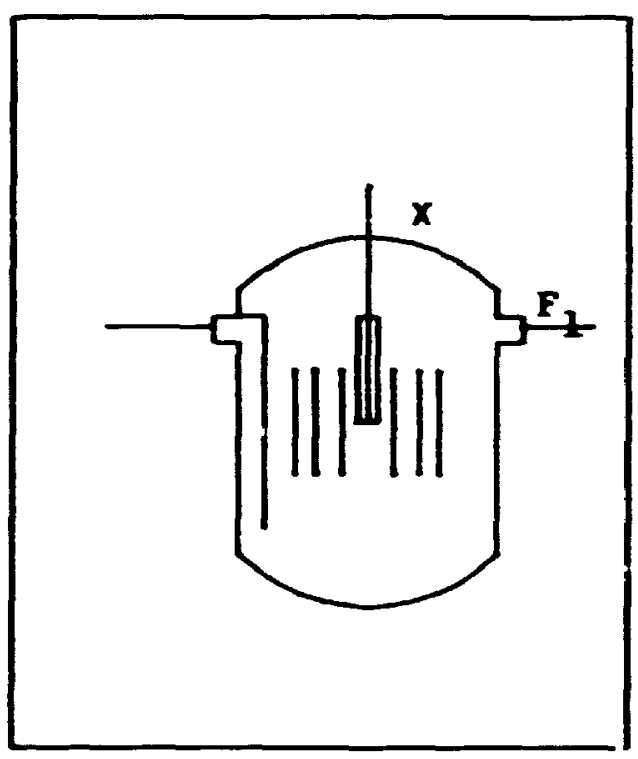

reacr effect eopion

$$
\frac{d}{a} O_{1}=C_{1}\left(x_{1}-x_{r}\right) O_{1}
$$

erresy boluce eouation

$$
\frac{d}{d} u_{n}=F_{i}\left(u_{2}-u_{1}\right)+Q_{1}
$$

Fipure 2. Rascior moded

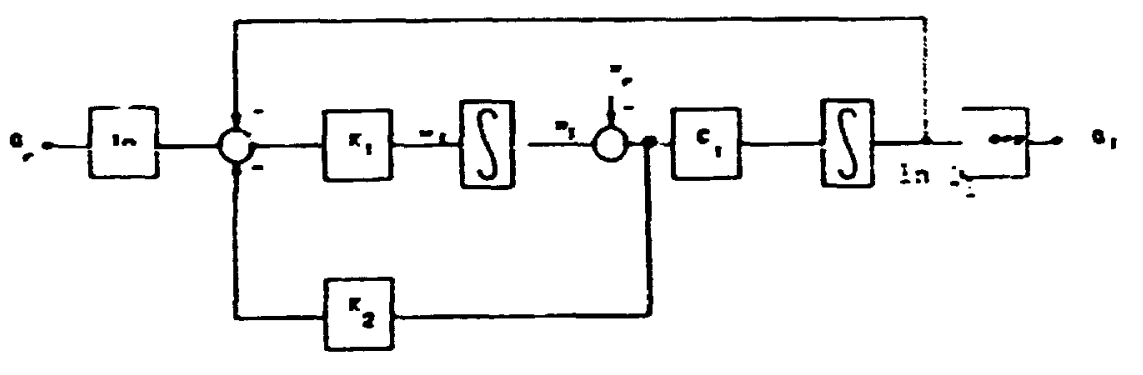

Figure 3. Reactor rod bank dyramics

reaclor rod dynamics

$$
w_{1}=\frac{d}{d} x_{1}=K_{r}\left(\ln \frac{Q_{r}}{Q_{1}}-K_{2}\left(x_{1}-x_{r}\right)\right)
$$


The reactor equations used are quoted with figure 2. Onily the energy belance equaion (2.2) is uscel for the reactor vessel water volume. assuming constan water mass. An estimation of tix reatur rextivity constand $C_{1}$ from more accurace kinctic equations is performed in appendix $A$. The reactur effect $Q_{1}$ is determined ond by the control rod position $x_{1}$ which is governed by a control mechansen

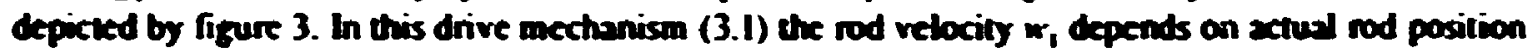
$x_{1 .}$ the retio of rexctor effect demand $Q$, and actual effect $Q_{2}$. Covosine appoppriate values for the controlline constants $K_{1}$ and $K_{2}$ incended values for the condrol boop frequency and dempine ratio may be achieved given suitable smooth bent movemen (ef. 3.2.3).

Process variables sebanitied to arto/manual control and malfunction handine are control rod refierence $x$, and velocily $w_{1}$ (cf. 3.4.5). Also an inpur consume strould be specified to the model limitating the speed of the rod bank to a fixeo maximal rate.

\subsection{Pump model}

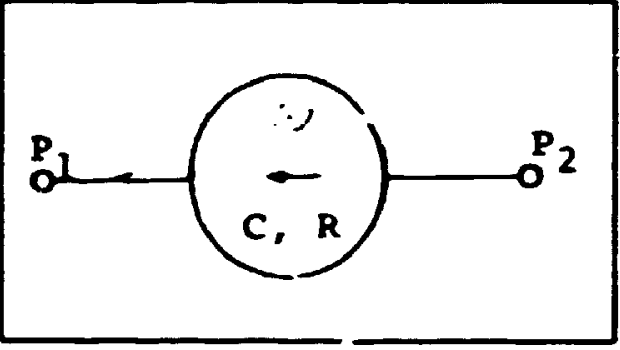

Figure 4. Pump model

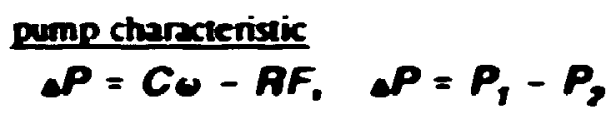

The model. shown in figure 3. simulates four centrifugal pumps: primary cooling (20). feed water (21). cooling waker (22) and volume control puanp (23). Allhough only the feed water and the volume contiol pump are treated

as pumps driven by variable speed motors. all pump/motor systems are implemented by the same prototype model. This contributes to convenicnce in programming and consistency in treament of pump paraneters. Further it is only tre qualitative behavior of the pump system which have interest to the power plank model. and hence the pump characteristic is aproximated by a simple linear expression (3.1) connecting the pressure head $D P$ shan angular velocity $u$ and mass fow rate $f$. The pump constank $C$ and the pump finction factor $R$ are cstimaed from mass fow rale and pump velocity under steady state conditions and not from real puinp data.

The pump model also includes two real-vaived process parameters. an error paraneter for malfunction capabilities. which simulates accidents such as loss of power and failed pump speed. and an autohnanual nag for manual operation (cf. 3.4.4). 


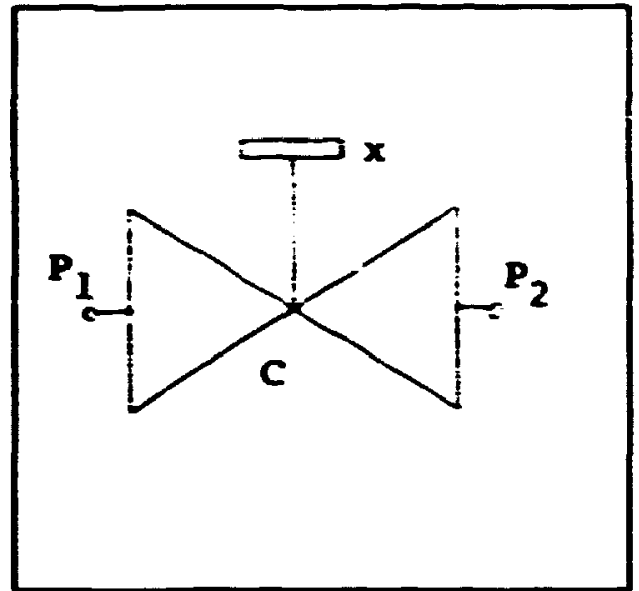

Figure 5. Contol retre moded valve charactistic

$$
\begin{aligned}
F=x C \Delta P . \quad P & =P_{1}-P_{2} \\
0 & \leqslant x \leqslant 1
\end{aligned}
$$

The operaiond equation is linearizes in arogy 0 the penp modet. as exact quanitative valve behavior is of minor intecest for the simulation pupose and further this is comvenien in deline with the notione equations (d. 3.1.8). The moded also iachedes two real-valued process

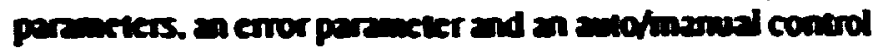

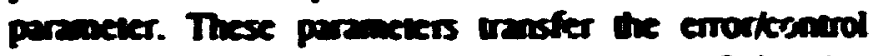
inpar values to the value position poraneter (cf 3.4.1).

\section{1 .4 Safty Valve model}

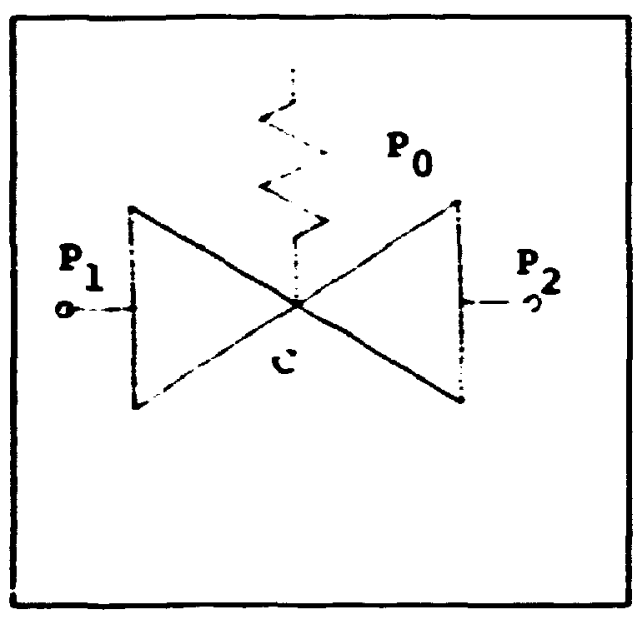

Figure 6. Sately velve model valve charectenistic

$$
\text { F } \begin{aligned}
=x C \perp P . & P=P_{1}-P_{2} \\
x & = \begin{cases}0 & P<P_{0} \\
1 & A P_{2} P_{0}\end{cases}
\end{aligned}
$$

This valve model operates with a linear charackeristic of the sane form as the conurol valve. but the valve position is treated as an intermal parameter put to zero under normal conditions, but reised 10 unity when the pressure differential exceeds the pressure setpoinh. or it may be set to an intermediate value by an error paraneter for simulation of a stuck valve (cf. 3.4.2). 


\subsubsection{Pressurizer model}

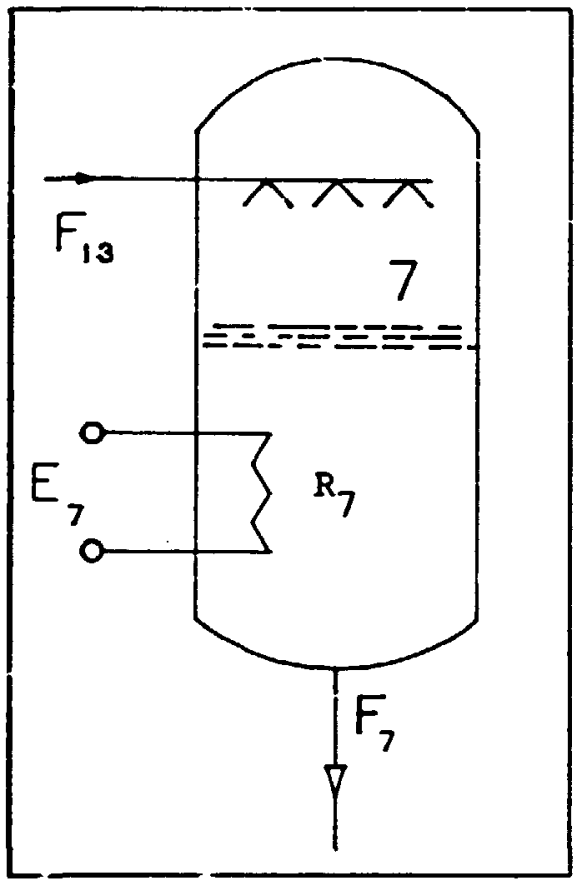

dynamic equations

$$
\begin{gathered}
\frac{d}{d t} U_{7}=F_{13} u_{2}-F_{7} u_{7}+Q_{7} \\
\frac{d}{d t} M_{7}=F_{13}-F_{7}
\end{gathered}
$$

where

$$
\begin{aligned}
& Q_{7}=\frac{E_{7}^{2}}{A_{7}} \\
& U_{2}=\frac{U_{2}}{M_{2}}
\end{aligned}
$$

Figure 7. Pressurizer model

$$
u_{7}= \begin{cases}h_{1}\left(P_{7}\right) & \text { for } F_{7} \geq 0 \\ u_{1} & \text { for } F_{7}<0\end{cases}
$$

\section{two-phase equations}

$$
\begin{gathered}
\alpha_{7}=\frac{V_{i 7}}{V_{7}} \\
U_{7}=V_{7}\left(\alpha_{7} \rho_{i}\left(P_{7}\right) h_{7}\left(P_{7}\right)+\left(1-\alpha_{7}\right) \rho_{9}\left(P_{7}\right) h_{0}\left(P_{7}\right)\right) \\
M_{7}=V_{7}\left(\alpha_{7} \rho_{7}\left(P_{7}\right)+\left(1-\alpha_{7}\right) \rho_{9}\left(P_{7}\right)\right) \\
T_{7}=T_{0}\left(P_{7}\right)
\end{gathered}
$$

The pressurizer is implemented with a single cooling spray armature and a :ieater element for pressure control (figure 4). The pressurizer spray flow $F_{13}$ are taken from the cold leg of the primary loop and controlled by the spray flow control valve. The heater is controlled by a variable voltage $E$, The pressurizer is nomally filled with nearly equal volumes of saturated water and steam, and the applied 
Iwo-phase equations (7.3-4) are solved for pressurc and relative water volume from the total energy and mass of the water/steam content ( $/$ ind.1982). This involves solution of non-lincar equations performed by an iterative zero finding procedure $(L \quad$ g.1980) used on a linear expression of some auxilliary functions composed by the steam and water density and enthalpy functions. For details, see appendix $A$. The pressurizer energy and mass balance equations (7.1-2) are then evaluated using the pressurizer spray and outlet flows $F_{13}$ and $F_{7}$, heater ersact $Q_{7}$ and specific energies $u_{2}$ and $u_{7}$ for primary water and pressurizer outlet flow. For positive outlet flow $F_{7}$ the energy $u_{7}$ is calculated as enthalpy of pressurizer water, for negative as energy of primary circuit (hot) water.

The pressurizer is treated as a thermal isoiated system, and no attempt is used to allow for the limited heat exchange between the system and the reactor. The pressurizer mean temperature $T_{7}$ is calculated from the mean pressure alone by the temperature function $T_{3}(P)$ for saturated steam. The pressurizer heater voltage may be set manually by a control parameter, and may be disconnected entirely by a malfunction pa.ameter (cf. 3.4.6). 


\subsubsection{Steam Generator model}

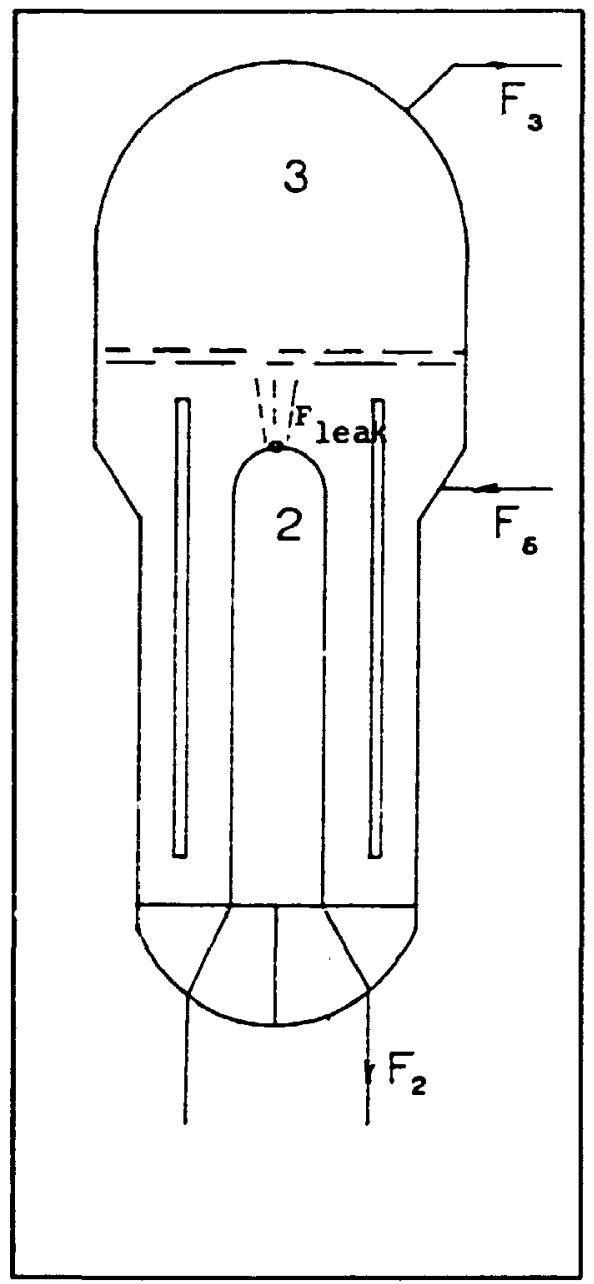

heal transfer

$$
Q_{23}=a_{3} K_{23}\left(T_{2}-T_{3}\right), a_{3}=\frac{V_{1}}{V_{3}}
$$

dynamic equations (tube side)

$$
\begin{aligned}
& \frac{d}{d t} U_{2}=F_{2}\left(u_{1}-u_{2}\right)-Q_{20} \quad u_{1}=\frac{U_{1}}{M_{1}} \\
& u_{2}=\frac{U_{2}}{M_{2}} \\
& M_{2}=\text { constant }
\end{aligned}
$$

dynamic equations (shell side)

$$
\begin{gathered}
\frac{d}{d t} U_{3}=F_{5} U_{5}-F_{3} u_{3}+Q_{23}+F_{\text {mat }} U_{2} \\
\frac{d}{d t} M_{3}=F_{5}-F_{3}+F_{\text {mat }} \\
T_{3}=T_{5}\left(P_{3}\right)
\end{gathered}
$$

Figure 8. Steam generator model

two-phase equations (shell side)

$$
\begin{gathered}
U_{3}=V_{3}\left(\alpha_{3} P_{1}\left(P_{3}\right) h_{f}\left(P_{3}\right)+\left(1-\alpha_{3}\right) \rho_{d}\left(P_{3}\right) h_{d}\left(P_{3}\right)\right) \\
M_{3}=V_{3}\left(\alpha_{3} P_{1}\left(P_{3}\right)+\left(1-\alpha_{3}\right) \rho_{9}\left(P_{3}\right)\right)
\end{gathered}
$$

The steam generator model is quoted with figure 5 . In the tube side only the energy balance equation (5.2) is used as the tube water mass is asstr...ed constant in time (5.3). The shell side is treated analogous to the pressurizer, and the two-phase e aluation routiase (cf. appendix B) is used to determine relative water level $\alpha_{3}$ and steam pressure $r_{3}$. For the malfunction purpose the heating tube is allowed to surpass the water level, in fact a serious accident in a real power plant, and hence the transmitted heat effect are set proportional to both mean temperature difference between tube and shell 
side and relative water level (5.1). Steam mean temperature $T_{3}$ is calculated from the saturated steam temperature function $T_{3}(P)$. Malfunction capability in the steam generator, representing primary circuit in this connexion, is implemented by the possibility of a steam generator tube leak (cf. 3.4.8).

\subsubsection{Condenser model}

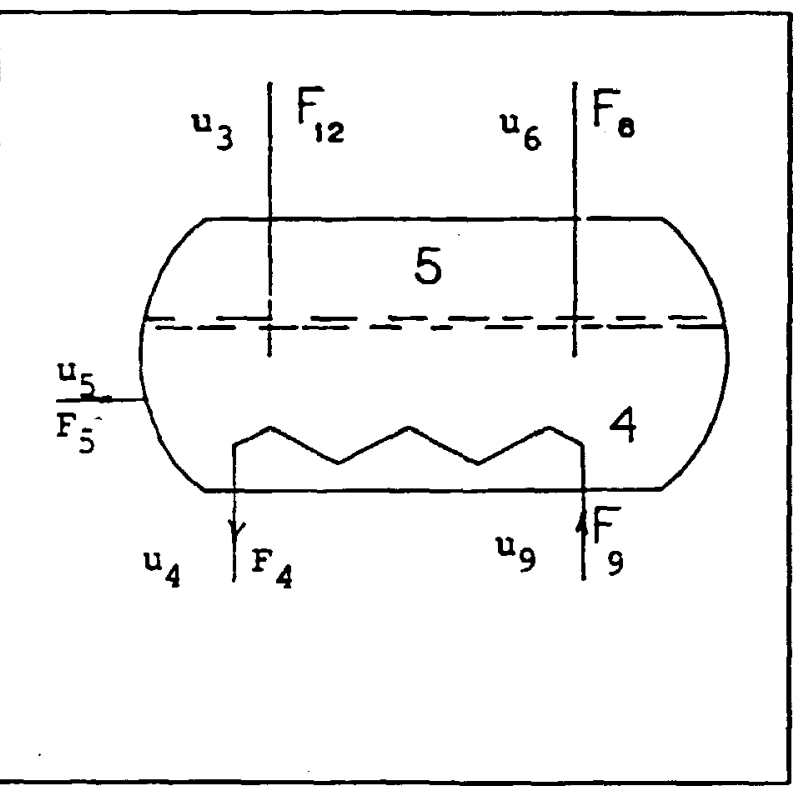

heat transfer

$$
Q_{45}=K_{45}\left(T_{4}-T_{5}\right)
$$

dynamic equations (tube side)

$$
\begin{gathered}
\frac{d}{d t} u_{4}=F_{0}\left(u_{0}-u_{4}\right)-Q_{45}=0 \\
u_{4}=C_{p} T_{4} \\
u_{0}=C_{p} T_{0} \\
T_{4}^{(\infty))}=\frac{F_{0} u_{0}+K_{45} T_{5}}{F_{0}+K_{45}}
\end{gathered}
$$

Figure 9. Condenser mociel

dymamic equations (shell side)

$$
\begin{gathered}
\frac{d}{d t} U_{5}=F_{12} u_{3}+F_{8} u_{6}-F_{5} u_{5}+Q_{45}, \quad u_{3}=h_{d}\left(P_{3}\right) \\
\frac{d}{d t} M_{5}=F_{12}+F_{6}-F_{51} \quad u_{5}=h_{1}\left(P_{5}\right) \\
T_{5}=T_{d}\left(P_{6}\right), \quad u_{0}=\frac{F_{96} h_{d}\left(P_{5}\right)+F_{10} h_{f}\left(P_{5}\right)}{F_{90}+F_{10}}
\end{gathered}
$$


two-phase equations (shell side)

$$
\begin{gathered}
U_{5}=V_{5}\left(\alpha_{5} P_{\lambda}\left(P_{5}\right) h_{\lambda}\left(P_{5}\right)+\left(1-\alpha_{5}\right) P_{d}\left(P_{5}\right) h_{d}\left(P_{5}\right)\right) \\
M_{5}=V_{5}\left(\alpha_{5} P_{\lambda}\left(P_{5}\right)+\left(1-\alpha_{5}\right) F_{5}\left(P_{5}\right)\right)
\end{gathered}
$$

The condenser is modelled very similiar to the steam generator shell side assuming that both water and steam is present at saturated conditions. The two-phase calculation algorithm used for the stean generator and pressure determination due to the large range applicability of the approximated thermodynamical functions. The equations used for two-phase calculation (9.8-9) and the mass- and energy balance equations (9.5-7) and (9.2-4) are quoted with figure 9. However. the tube side of the condenser is treated different from the steam generator tube assuming constant energy content as well as constant water mass. This approach prevents the dymamic of the system to degenerate into a stiff system system coping with small characteristic time constants. and hence we replace the dyaamical equations with an algebraic equation (9.4) for determination of tube temperature $T_{4}$ from shell side temperature $T_{3}$, cooling water flow $F$, and specific water energies evaluated from (9.3) expressing proportionality between specific energy and absolute temperature by the heat capacity coefficient $C_{\mathrm{p}}=$

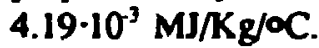


3.1.8 Turbine/Generator model

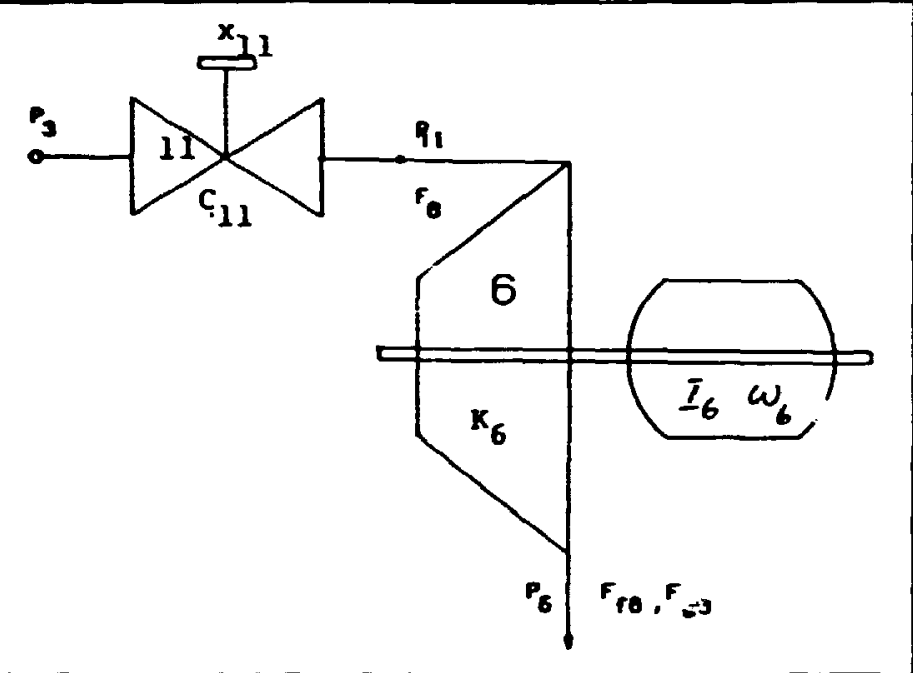

generator equations

$\frac{d}{d t} E_{k+s}=W_{0}-W_{0}$

$E_{1+\text { in }}=\frac{1}{2} I_{0} \omega_{0}^{2}$

$w_{0}=\frac{v^{2}}{R_{0}}$

Figure 10. Turbine/Generator modei

$V_{B}=K_{\omega_{B}}$

thermodynamical turbine equations

$$
\begin{aligned}
& F_{8} s_{g}\left(P_{11}\right)=F_{g 8} s_{d}\left(P_{s}\right)+F_{f 8} s_{d}\left(P_{s}\right) \\
& F_{6}=F_{g \theta}+F_{10} \\
& W_{6}=F_{6} h_{\alpha}\left(P_{11}\right)-F_{86} h_{\alpha}\left(P_{6}\right)-F_{18} h_{1}\left(P_{5}\right)
\end{aligned}
$$

Now rale balance equation

$$
F_{6}=K_{8}\left(P_{11}-P_{5}\right)=x_{11} C_{11}\left(P_{5}-P_{11}\right)
$$


Sow rate calculat: n

$$
F_{8}=\frac{x_{11} C_{1}:}{x_{11} C_{11}} \cdot \frac{K_{8}}{K_{8}}\left(P_{3}-P_{5}\right)-x_{11} \frac{C_{11} K_{8}}{C_{11}+K_{8}}\left(P_{3}-P_{5}\right)
$$

The lurbine ( $\mathrm{Ii}_{\mathrm{i}} \mathrm{U}$ : $: 10$ ) is modelled in a simple way neglecting all dynamic effects (Lind,1982). In the turbine flow ratt: disulation it is $\mathbf{t}$ ' $n$ convenient to consider the turbine and the turbine valve as an integrated comp: or:ent combining th: turbiae valve characteristic equation with the turbine flow rate equation (10.7). Turbine inlet fow $F_{6}$ is then calculated using the general control valve model with

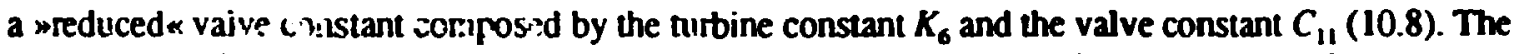
turbine outlet flos s oi saturaicd steam and water (10.4-5) are then calculated by means of the entropy functions foi warer and $s^{\prime} e$ arm assuming ideal isentropic conditions. The mechanical energy $W_{6}$ produced is calculated by tie eneray balance equation (10.6).

The generator :quaiions (1:-3) simulates the generator as a dynamic system acting as a storage for kinetic energ. $E_{\text {kir }}$ ive to risument of inenia $l_{6}$ and shaft angular velocity $\omega_{6}$. The magnetizing current of the gererator is ss: tine's constant in time yielding propontionality between shaft angular velocity and generatur o!:tpi $t$ viltage $V_{6}$. The voltage is controlled by the power controller component (32) which affects the l.ittire vaive and hence the mechanical turbine energy $W_{6}$ produced. The moment of ineria $l$. is estimisied such that the generator system manifests a characteristic time period $t_{c}$ of about 10 seconis fo a fu.jizing a possible difference between electrical energy $W_{c}$ and turbine eneigy $W_{6}$ with nominal linas resisiance $R_{6}$.

The turbine/general sr systcti is modelled by a malfunction parameter for accidental loss of generator voltage and a control parameit: for turbine trip capability (3.4.7). 


\subsubsection{Volume control tank model}

The volume control tank componen (8) is modelled as a storaze of mass only using the mass baiarce equation

$$
\frac{d}{d} M_{b}=F_{M}-F_{0}
$$

assuming that the specific energy is constant due to thermal coupling between inlet and oultet Rows. There is no malfunction capability implemented for the volume control tank.

\subsubsection{Lubrication systems}

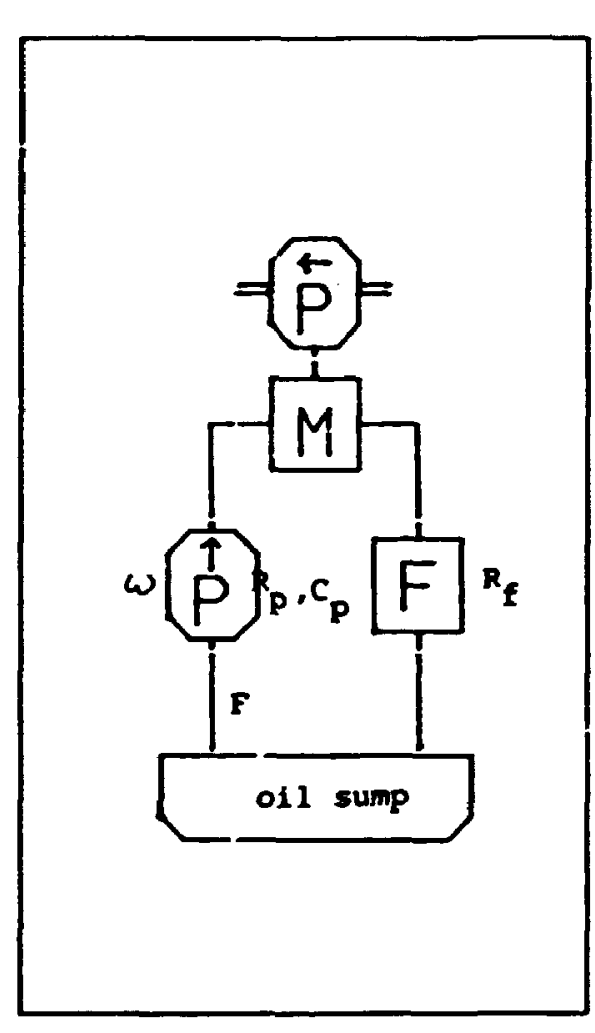

Figure 11. Lubrication systems
Two oil lubrication systems are implemented in the power plant model, one for the primary coolant pump and the other for the feedwater pump. The lubrication system modelled is quoted with figure 11 . This model implements a simple oil supply circuit consisting of an oil pump model implemented by use of the general pump model and an oil temperature function. The oil flow rate is estimated from oil pump parameters $\omega . C_{p}, R_{p}$ and the filier friction constank $R_{t}$ (11.l). The nil iemperature is estimated from the very simplified remperature function (11.2) expressing inverse proportionality between oil flow and temperature. The temperature coeificients are estimated such that oil temperature is about 60 Celcius degree for nomal oil flow rate $(0.01 \mathrm{Kg} / \mathrm{s})$ and about 500 Celcius degree for stopped now.

$$
\begin{gathered}
F=\frac{C_{p} \omega}{R_{b}+R_{1}} \\
T=15.0^{\circ} C+\frac{0.5}{F+10^{-3}} \cdot C
\end{gathered}
$$




\subsection{Filter systems}

Besides filter components in the ofl lubrication sytem a filter component in the cooling waler circuit is implemented. Similiar to the oil filter implementations the couling water filter is simply modelked by a friction constant added to the purmp friction parameter in the cooling water pump flow model. No special malfunction parameter for filier components are implemented in the plane model. but malfunctions due to filter blocking may be achieved assigning appropriate high values to the filter constents.

\subsection{Control system representation}

\subsection{Automatic controller models}

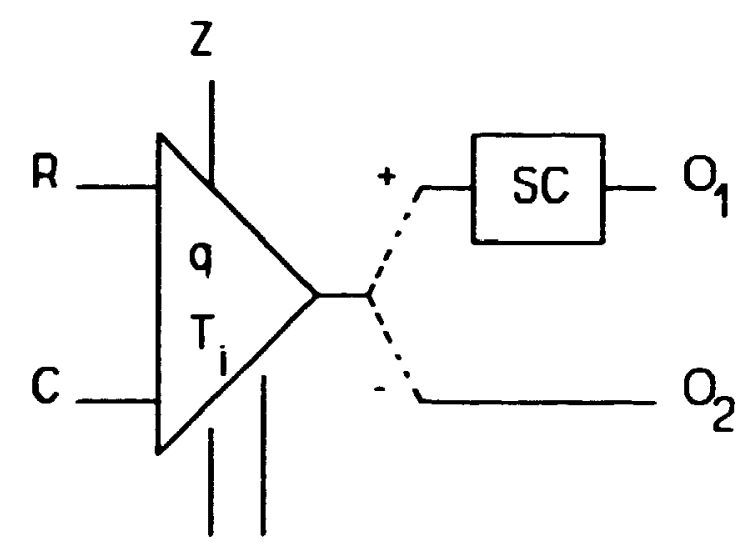

CTL ERR

The power plant model implements two types of general automatic controllers. a one-output controller used for steam generator level and pressure control and gencrator voltage control, and a two-outpul controller used for pressurizer level and pressure control.

Both controilers models are PI (proportional-integral) type controllers with nearly the same function. the two-output controller may be considered an exiension of the one-output controller by addition of a switch and a scaling constant.

Figure 12. Controller model

The controller models include the frilowing parameters (figure 12): a setpoint reference $R$. controlled input signal $C$. proporional cons:ant $q$ and reset time constant $T_{1}$, state (reset) parameter $Z$, control signal $S$ and one or two outpui parameters $O_{1.2}$. For two-output controllers the switch position is governed by the signs of the control signal $S$. For malfunction and auto/manusl capability the models also include a control parameter and an enror parameter. The state variable $Z$ is only changed when the emor signal is less tha 20 per cent of the setprint value. and hence the controller is functioning as a pure proporional controller for large deviances from the setpoint. 
Figure 13 summarizes all controllers used in the power plant model with associaled controlled and activaled process variables.

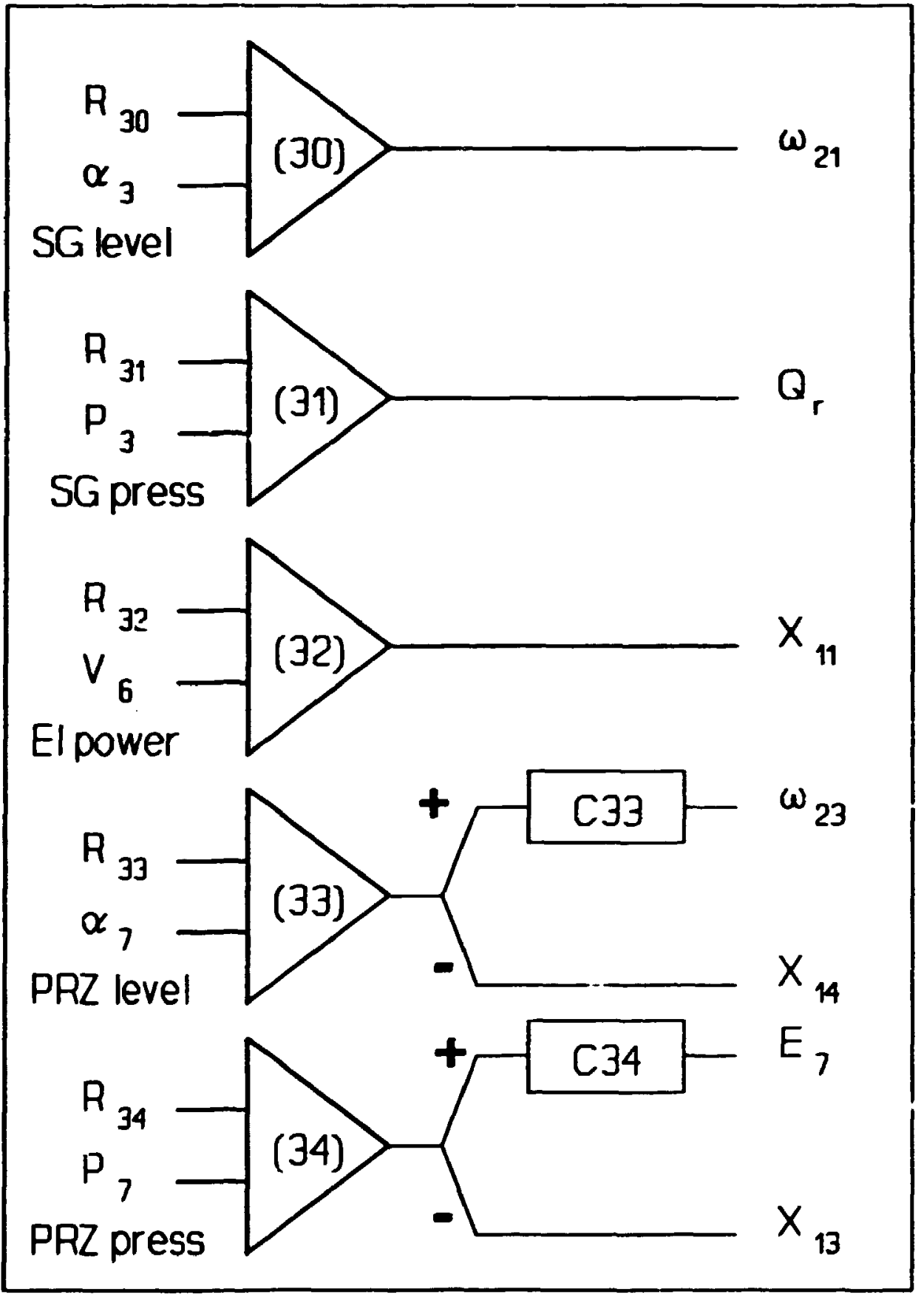

Figure 13. Plant controllers 
The intemal controller circuit logic common to both controller types is shown in figure 14. Also stated is the two closed control loop iransfer functions $H(s)$. estimated from two selecied forms for plant transfer functions $F(s)$. These expressicns are used for estimation of the controller constants $q$ and $T_{\text {r }}$. (cf. 3.2.2).

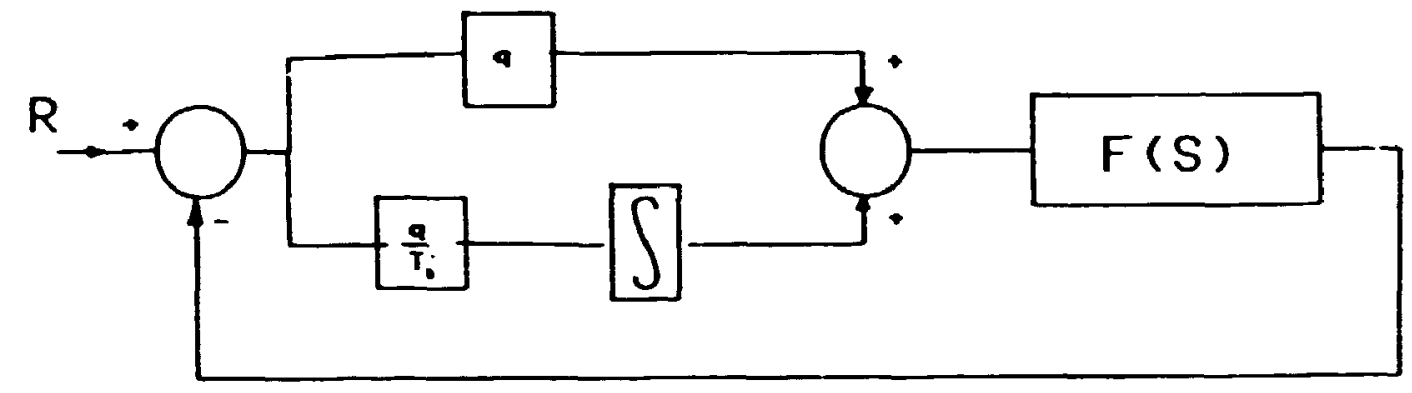

Figure 14. Controller logic

$$
\begin{aligned}
R(s) & =\frac{K}{s} \\
H(s) & =\frac{q K\left(s+\frac{1}{T_{i}}\right)}{s^{2}+q K s+q \frac{K}{T_{1}}} \\
q & =\frac{0.87}{K t}, T_{i}=0.87 t \\
R(s) & =\frac{K}{1+b_{0} s} \\
H(s) & =\frac{\frac{q K}{T_{i} t_{0}}\left(s T_{1}+\eta\right.}{s^{2}+\frac{1+q K}{t_{0}} s+\frac{q K}{T_{i} t_{0}}} \\
q & =\frac{0.87 \frac{b_{0}}{t}-1}{K}, T_{1}=t\left(0.87-\frac{t}{b_{0}}\right)
\end{aligned}
$$




\subsection{Controlke dimensioning}

With exception of controller (32) for generator voltage control. the four controllers (30). (31). (33) and (34) for steam generator kevel. steam generator pressure. pressurizer level and pressurizer pressure control are all dimensioned according to the simplifying main assumptions: all controller loops are mutual independant and the plant trensfer function $F(s)$ for each controller loop (figure 14) are of ixe simple type (14.1) or (14.2) corresponding to either linear or exponential shaped time step responses. Naturally this is a heavy simplification as the control circuits are strongly non-linear. and should be considered from a multivariable system point of view. taking mutual infuences into account. Estimated plaxt time response functions due to inpult unit step functions are leading to the following plant uransfer function estimations

Table 3. Transfer funcrion estimation

\begin{tabular}{|c|c|c|c|}
\hline $\begin{array}{c}\text { Control- } \\
\text { ler }\end{array}$ & $\begin{array}{l}\text { plant transter } \\
\text { tunction type }\end{array}$ & $\begin{array}{l}\text { transfer function } \\
\text { parameters }\end{array}$ & $\begin{array}{l}\text { switch } \\
\text { constant }\end{array}$ \\
\hline (30) & Ks & $K=4.7 \cdot 10^{.5} \mathrm{sec}^{-1}$ & - \\
\hline (31) & $K(1+65)$ & $\begin{array}{l}K=0.26 \mathrm{bar} M W W \\
b_{0}=97 \mathrm{sec} .\end{array}$ & - \\
\hline (32) & not estimated & & \\
\hline (33) & $\mathrm{Ks}$ & $K=-3.8 \cdot 10^{-4} \mathrm{sec}^{-1}$ & $C_{20}=1180 \mathrm{rm}$ \\
\hline (34) & Ks & $K=-0.26 \mathrm{bar} / \mathrm{sec}$ & $c_{30} 107 \mathrm{~V}$ \\
\hline
\end{tabular}

These estimations of plant transfer functions docs not involve the two-outpul controller switch constants for controllers (33) and (34) (figure 12) as the negative controller switch positions are used comesponding to changes of value positions $X_{14}$ for let down flow and $X_{13}$ for spray now rate. The controller switch constants are detemined graphically switching the controllers to positive position and varying the constants such that step responses for unchanged input steps shows positive slopes of the same magnitude. The values for the constants determined in this way are staled in table 3.

The internal controller constants, proportional factor $q$ and reset time $T$, should now be estimated from the complex pole configuration of the closed loop transfer function $H(s)$ for (wo cases considered (figure 14). The complex pole configuration depends on estimated values for closed controller loop time constant $r$ (reciprocal loop frequency) and damping of about 30 degrees, we gei the formulas in (14.1) and (14.2) for determination of the controller constants.

Table 4 shows the estimated time constants and the evaluated controller cons'unts. 
Table \& - Controller conseanis

\begin{tabular}{|c|c|c|c|}
\hline $\begin{array}{l}\text { controt } \\
\text { ler }\end{array}$ & $\begin{array}{l}\text { time constan } \\
t \text { (esimeted) }\end{array}$ & $\begin{array}{l}\text { proportional } \\
\text { constant } 9\end{array}$ & $\begin{array}{l}\text { reset ine } \\
\text { constam } T .\end{array}$ \\
\hline (30) & $70 \mathrm{sec}$ & 526 m & $121 \sec$ \\
\hline (31) & $60 \mathrm{sec}$ & 9.6 mw/or & $73 \sec$ \\
\hline (32) & $10 \sec$ & $12 \cdot 10^{-5} \mathrm{~V}^{\prime}$ & $0.05 \sec$ \\
\hline (33) & $100 \sec$ & 45.5 & $173 \sec$ \\
\hline (34) & so sec & 0.074 bar' & $156 \sec$ \\
\hline
\end{tabular}

Condroller (32) for generalor voltage tates up an exceptional position as the dynamies of the generator system (3.1.8) couples to the rest of the plan model in 2 way 100 complicaled for the simple controller tunine procedure described above. and thus the controller coesentes in coble 4 for this controller are estimated graphically by experimen kading 10 a reasomably controlled bethaviour of the generator vollage.

\subsubsection{Reactor rod bank kineties}

The movement of the reactor rod bank is controlked by the control bop depicted in figure 3. Calculating the transfer function for this loop we may estimate the loop consianks $K_{1}$ and $K_{2}$ from the expressions

$$
K_{1}=\frac{1}{C_{1} 6^{2}}, \quad K_{2}=26 C_{16}
$$

where $t_{0}$ is the control loop time consian (recoprocal loop frequency). $\zeta$ the damping ratio and $C_{1}$ the reactor reactivity coefficient. The expressions are obtained choosing a time constan of 30 seconds. a damping ratio of 0.87 (trensfer function pole angles about 30 degrees) and the value of the reactivity coefficien $C_{1}$ estimaed in appendix $A$.

\subsection{Plant component interaction}

The power plant consists of two main loops. the primary coolant loop and the secondary steam line loop. While the steam line flow rates are simple to estimate depending only on the steam line valve position and the feedwater pump velocity, the primary coolane now rate and pressure calculations is somewhat more intricate. 


\subsection{The pribury croland system approach}

The mass bolance equarions for the primary fow rees ace calcubled by the follo ring expressions derived from figure 15

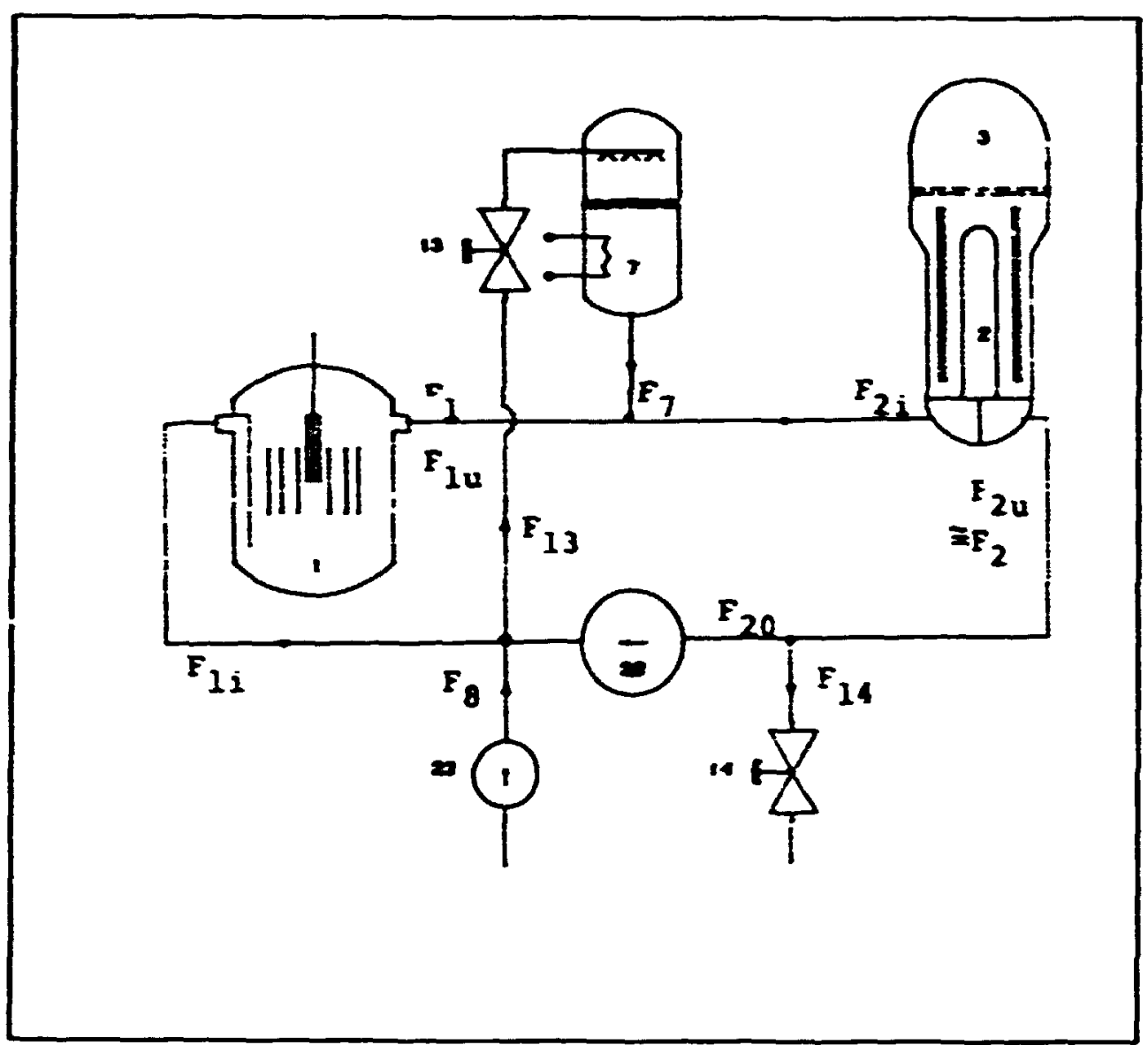

Figure 15. Cookent system, mass and presssure balance

mass bolance ecuations

$$
\begin{aligned}
& F_{n I}=F_{0}+F_{g}-F_{89} \\
& F_{20}=F_{20}+F_{14} \\
& F_{T}=F_{z}-F_{10}
\end{aligned}
$$

$$
\begin{aligned}
& F_{10}=F_{u}+v_{1} \frac{d_{p}}{d t} \frac{\sigma_{1}}{d} \\
& F_{z}=F_{a}+V_{2} \frac{d \rho_{m}}{d T} \frac{d T_{2}}{d}+F_{m}
\end{aligned}
$$


pressure balance equations

$$
\begin{gathered}
P_{1}=P_{7}+R_{1} F_{1} \quad(15.6) \quad P_{2}=P_{7}+R_{2} F_{2} \\
R_{1} F_{1}+R_{2} F_{2}+R_{20} F_{20}=C_{20} \omega_{20}+D P_{200}
\end{gathered}
$$

where

$$
D P_{s=}=g\left(\rho_{w}\left(T_{2}\right)-\rho_{w}\left(T_{1}\right)\right)\left(h_{1}+h_{2}\right)
$$

Equations (15.2) and (15.4) are derived from the general expression

$$
V \frac{d}{d t} \rho_{w}=V \frac{d}{d T} \rho_{w} \frac{d T}{d t}=F_{1}-F_{u}
$$

expressing mass flow change for inlet and outlet flow rates for a volume $V$, assuming quasi stationary pressure conditions, so that specific density $\boldsymbol{p}_{w}(\eta)$ only depends on temper-'ure $T$. This equation used for dynamical mass flow contributions for reactor vessel and steam generator tube side water volimes, taking density changes into account. contributes to a more accuiate determination of pressurizer flow rate $F_{7}(15.5)$.

The model approach also considers the effect of natural coolant circulation due to the U-type shaped flow paths for bnth steam generator tube and reactor vessel water volume giving the static pressure $D P_{\text {stat }}$ for the reactor and steam generator systems (15.9) where $\rho_{w}\left(T_{2}\right)$ and $\rho_{w}\left(T_{1}\right)$ denote specific densities of cold and hot coolant water in the reactor legs, and $h_{1}$ and $h_{2}$ the geometrical heights of the reactor vessel and steam generator tube.

The pressure balance equation in the coolant system (15.8) is obtained srom the linearized pump and valve characteristics and the pressure drops through reactor vessel and steam generator tube using some estimated friction cuefficients $R_{1}$ and $R_{2}$ (15.6-7). $P_{2}$ issure and flow variables in the coolant system can now be now determined in sequence.

Charge and release flow rates $F_{8}$ and $F_{14}(16.1-2)$ are estimated by the charging pump and let down valve usir $z$ the genernl pump and control valv. ninodels with pressurizer pressure $P_{7}$ alone, neglecting the (minor) pressure w.ops through the other coolant loop component:. This approximation alleviates the pressure calculation avoiding implicit equation solving strategies.

$$
\begin{gathered}
F_{1}=\frac{\left(C_{29} \omega_{23}-P_{7}\right)}{R_{23}} \\
F_{14}=x_{14} C_{14} P_{7}
\end{gathered}
$$


Coolant pump flow rate $F_{20}(16.3)$ is deteminicu from (15.8) and calculated by the general pump flow model using a reduced pressure head $D P_{20}{ }^{\circ}$ (16.5) and pump friction parameter $R_{1}{ }^{\circ}$ (16.4) depending on the state of the spray flow valve and charging components. The linearized pump and valve characteristics contribute much for simplicity in derivation of these expressions.

$$
\begin{aligned}
F_{20} & =\frac{\left(C_{20} \omega_{20}-D P_{20}^{\prime}\right)}{R_{1}^{\prime}+R_{2}+R_{20}} \\
R_{1}^{\prime} & =\frac{R_{1}}{1+x_{15} C_{19} R_{20}} \\
D P_{20}^{\prime} & =R_{1}^{\prime} F_{1}+R_{2} F_{14} D P_{20}
\end{aligned}
$$

where

$$
\left.D P_{s=0}=g\left(\rho_{w}\left(T_{2}\right)-\rho_{m}\left(T_{1}\right)\right) i h_{1}+h_{2}\right)
$$

Next the spray flow rate $F_{13}(16.7)$ is calculated using the control valve model with pressure drop determined from (16.8)

$$
F_{13}=x_{13} C_{13} D P_{13}
$$

where

$$
D P_{13}=R_{1} F_{1}=R_{1}^{\prime}\left(F_{g}+F_{a 0}\right)
$$

and then the reactor and steam generator flow rates $F_{1}$ and $F_{2}$ are calculated using (16.9) and (16.10).

$$
F_{1}=F_{20}+F_{g}-F_{1 s}
$$

$$
F_{2}=F_{20}+F_{14}-F_{\text {mat }}
$$


Finally the pressurizer flow $F_{7}$ is calculated from (16.11) derived from (15.5).

$$
F_{7}=F_{13}+F_{14}-F_{0}+V_{1} \frac{d \rho_{w}}{d T} \frac{d T_{1}}{d t}+V_{2} \frac{d \rho_{w}}{d T} \frac{d T_{2}}{d t}
$$

where

$$
\begin{aligned}
& \frac{d T_{1}}{d \dot{d}}=\frac{1}{M_{1} C_{p}} \frac{d U_{1}}{d t} \\
& \frac{\partial T_{2}}{d t}=\frac{1}{M_{2} C_{p}} \frac{d U_{2}}{d t}
\end{aligned}
$$

The temperature gradients in these form!las are approximated by the expressions (16.12) using proportionality between absolute temperature and total energy $U$

$$
U=M C_{p} T
$$

where $C_{\mathrm{p}}=4.19 \cdot 10^{-3} \mathrm{MJ} / \mathrm{Kg} / \mathrm{OC}$ is the heat capacity coefficient for constant pressure.

This temperature approximation is considered sufficient accurate for calculation of these gradients, although the nominal temperature for the primary coolant falls outside the domain for this equation. 


\subsection{Activity concentration propagation}

Figure 16 shows the secondary loop of the plant together with the equations for calculation of activity concentration propagation in the steam line and condenser in case of a steam generator tube leak (cf. 3.4.8). The activity concentration in a specific component is defined as the relative mass ratio between the mass of the present coolant leakage and the total inventory mass. Equations (16.1) and (16.2) determine the activity state variables $C_{3}$ and $C_{5}$ describing the dynamics of activity concentrations in the steam generator and confenser shell side, and equations (16.3-5) determine the activities in the turbine $C_{6}$. safety valve out llow $C_{10}$ and bypass valve $C_{12}$.

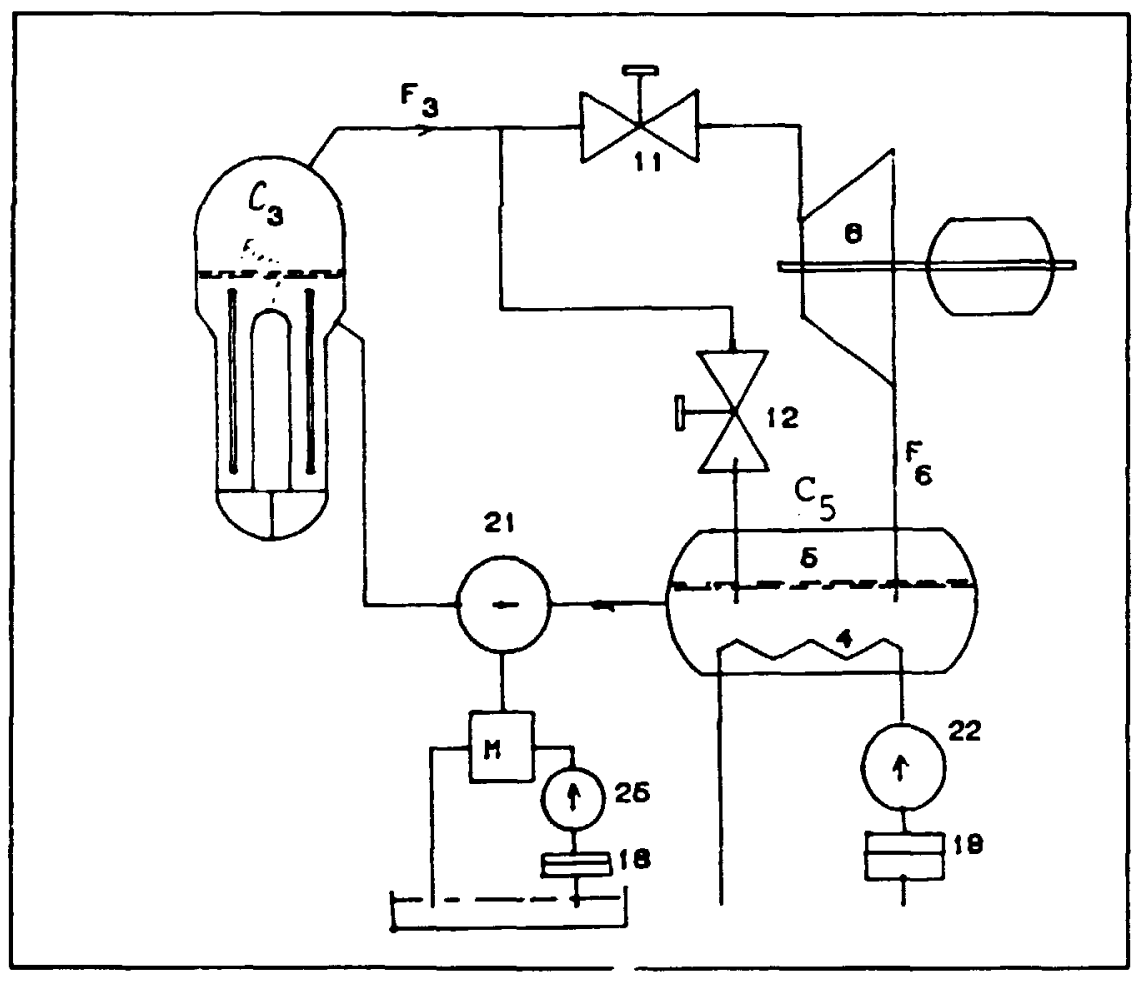

Figure 16. Secondary steam line loop

activily concentrations

$$
\begin{array}{rlrl}
\frac{d}{d t} c_{3}=\frac{\left(C_{5}-C_{3}\right) F_{5}+\gamma_{2} F_{\text {max }}}{M_{3}}(16.1) & \gamma_{2}= \begin{cases}1 & \text { for } F_{\text {max }} \geq 0 \\
C_{3} & \text { for } F_{\text {max }}<0\end{cases} \\
\frac{d}{d t} c_{5}=\left(C_{3}-C_{5}\right) \frac{F_{3}}{M_{5}} & (16.2) & c_{6}=c_{3} \\
c_{10} & =c_{3} \\
c_{12} & =c_{3}
\end{array}
$$




\subsection{Malfunction and operator control capabilities.}

The general component models for valves, pumps and controllers include two real valued process parameters. a control parameter for auto/manual switching and an error parameter for malfunction capability. The control parameters are intended for manual setting of process variables, e.g. setting of valve positions. pump velocities and controller output values, while the error parameters should be used :o introduce disturbances to these values. Activation of malfunction and operator control is performed through the actual settings of error and control parameters. The general principle is that parameter values belonging to the unit interval (positive or negative) should be scaled to the actual control or malfunction process variables values while values outside the unit interval are ignored by the components.

The following table states typical control and malfunction possibilities and the relevant process parameters involved (cf. appendix E).

Control valves

- valve failed close/intermediate/open

CTL11-14

- manual valve position

CTL11-14

- accidental operating

ERR11-14

Safety valves

- valve failed close/intermediate/open

CTL10,15

Automatic controllers

- controller failed low/intermediate/high

CTL30-34

- manual output control

CTL30-34

- accidental selecting

ERR30-34

Pumps

- manual speed control

CTL20-25

- loss of power

CTL20-25

- pump failed off/intermediate/on

CTL20-25

- accidental operation

ERR20-25

Reactor

- failure in conisol rod bank position reference

ERR1

- reactor trip (control rod bank drop)

CTL1

- failure in control rod bank speed

ERR35

- manual control rod bank speed control

CTL35

Pressurizer heater

- loss of power

- manual power control

CTL7

- accidental operation

CTL7

ERR7

Turbine/generator

- accidental generator voltage ETRR6

- turbine trip

CTL6

Sieam generator tube leak

- leak size parameter

CLK2 


\subsubsection{Control valves}

The geiseral control valve model includes two real valued process parameicrs, an error parameter for mufunction capability (accidental operating valve) and a control parameter for auto/manual switching (e.g. valve getting stuck). A non negative control parameter value in the unit range is transferred to the valve position variable while other values are ignored. An error parameter value in the unit range increments the actual valve position value with this relative amount while other values are ignored.

\subsection{Safety valves}

The safety valve model includes only a control parameter for accidental manual selection, simulating a failed open, failed intermediate or failed closed valve. More complex malfunctions such as failure to reclose after opening is not possible with the actual model although it is by far the most common type of safety valve failure. There is no mechanism either for simulating a wrong setpoint. Similiar to the control valve only non negative parameter values in the unit range have any effect on the valve.

\subsubsection{Automatic controliers}

Like the control valve component the automatic controller components contain real valued parameters for malfunction handling and auto/manual control. The intension is that it should be possible to switch any automatic operating controller or failed controller to manual mode thus allowing a failed controller output to be manually reset. In this manual mode it should then be possible to control the component to any of its states even if these are not the desired ones for the process condition (e.g. primary pump off with reactor operating). The error parameter in the unit range modifies the controller outputs with this relative amount while other values are ignored. The control parameter are capable of generating the full range of controller output. so that values are scaled to output values. Control parameters for two-output controllers may have both positive and negative values due to the switching operating prinsiple (cf. 3.2.1).

\subsubsection{Pumps}

Similiar to the control valve component the general pump component model contain real valued parameters for malfunction capability (e.g. pump failed at intermediate speed) as well as auto/manual selection (e.g. loss of power. on/oif selection for fixed-speed pumps and rianual speed control for variable-speed pumps). The model scales non negative control parameter values from the unit range to pump speed to the range from zero to maximal pump speed allowed. Positive and negative values of the error parameter in the unit range increments the pump velocity with this relative amount while other values are ignored.

\subsubsection{Reactor}

In the reactor model the control rod bank position mechanism may be disturbed either by changing the control rod reference value $x_{r}$ corresponding to disturbance of critical reactor conditions, or by changes in the control rod bank velocity $w_{1}$ (cf. 3.1.1). Position reference disturbance is achieved through small signed values in the unit range of the error parameter ERiA1, and accidental reference position through non negative setting of the control parameter CTL1. Control rod bank velocity 
disturbance is achieved through analogous settings of the parameters CTL35 and ERR35. Notice that decreasing values is equivalent to a rod withdrawal and that incresing values correspond to roo insertion so that reactor trip may be simulated by setting these parameters to unity. Instantancous rod drop may be simulated setting the rod position state variable $X 1$ and speed variable W1 to zero.

\subsubsection{Pressurizer heater}

The pressurizer heater is modelled with a power control parameter $\mathrm{CTL7}$ and a heater disturbance parameter ERR7. Non negative control parameters are scaled to heater voltage frorn zero to maximal heater voltage. Small signed values in the unit range of the error parameter introduce heater disturbances.

\subsubsection{Turbine/Generator}

Generator outphi voltage V6 may be disturbed due to some generator malfunction by small signed values in the unit interval of the error parameter ERA6 and a turbine trip with loss of generator power as a consequence is signalled by non negative values of the control parameter CTL6. The model also provides for automatic turbine trip on generator overspeed. i.e. when the speed exceeds a maximal turbine speed. There is no malfunction parameter facility incorporated to deal with disconnection of load or load re-engagement, but the load resistance R6 may be changed in the mocel data base.

\subsubsection{Primary circuit leakage}

The simulator offers the ability to simulate a single leak in the steam generator tube. A leak is modelled in a very simple way setting the leak flow propontional to the presssure difference between tube and shell side of the steam generator. The magnitude of the leak coefficient CLK2 will depend on the leak size and may be estimated accodingly.

\subsection{Physical a!-.ms}

The computer model approach to the real physical power plant and the selected numerical methods used in the implementation involve that there may be process parameter conditions which transfer the system to states beyond physical reality. These conditions may either arise due to violations of some physical limitations, - e.g. a full or empty tank. temperature arguments outside defined ranges etc. or they may be caused by numerical algorithms implemented, e.g. a convergence failure in a root finding procedure. Physical alarms stops the model and generate messages in clear text with specification of the alarm type and the involved model components - e.g. „Pressuricer, High temperature limitk and calls for operator interveniance.

\subsection{Interlock and safety systems}

There is no automatic interlock and safety systems implemented in the power plant model as interlock and safety functions should be performed by a separate safe module external to physical plant model. Reactor trip should be trigged by high temperature, high power or loss of coolant flow etc. However. the only exception is that the turbine may trip itself due to overspeed ( $r$. 3.4.7). 


\section{References}

Achicser. N.I. (1956). Theory of Approximaion. New York.

Brenu. R.P. (1973). Algorims for Minimization without Derivation. Prentice Hall.

Fehtberg. E. (1969). Low onder classical Runge-Kulta formulas with step size control and their application to some hea transfer problems. Nasa repon TR R-315. Alabama.

Hojberg K.S. (1982). Power Planu Model for Display Experiments. Riso N-24-82.

Hunt G. (1984). Operator Control and Malfunction Capabilities. Lit nu. 320(3.3). note 2657. Haiden. Keeman. J. \& Keyes (1948). Thermodynanic properties of Sieam. John Wikey \& Sons. New Yor. Lang-Rasmussen. O. (1980). The Algol procedure ZERO. RMA Riso.

Lind. M. (1982). GNP - A Power Plank Model for Man-Machine experiments. Riso N-23-82.

VDI Wasserdampfiafeln, 6. auflage. Springer Vertag 1963.

Wiese. R. (1969). The Algol procedure RATCHEB, SA-129. Reactor Physics Departument. Riso. 


\section{A Neutron dynamics and reactor effect}

The basic equations is the one-dimensional kinetic equations for the concentration of prompt neutrons and aldayed neutrons $C$

$$
\begin{aligned}
& \frac{d}{d}=\frac{p-p}{l} n+\lambda C \\
& \frac{d c}{d}=-\lambda C+\frac{p}{l} n
\end{aligned}
$$

where $\rho$ denote the reactor reactivity, I neutron mean life time and $\rho$ fraction of total neutrons which is delayed neutrons with decay constant $\lambda$.

Equalizing equation (A I) to zero, assuming that the prompt neutron profile stabilizes few milliseconds afier a pertubation. we get from (A1) and (A2) the simplified first order differential equation for the nevtron concentration

$$
\frac{d n}{d \rho}=\frac{\lambda \rho}{\beta-\rho}
$$

In general the reactivity $\rho$ depends on several reactor parameters such as control rod position. reactor mean temperature and boron concentration. However, in the computer model we let the reactivity depend only upon reactor rod position $x_{1}$ and further the following approximation is made

$$
\frac{\lambda \rho}{\beta-\rho}=C_{1}\left(x_{1}-x_{0}\right)
$$

as the reactivity is vanishing for $x_{1}-x_{0}$. where $x_{0}$ is the rod position comesponding to critical reactor condition.

Using that the reactor effect $Q_{1}$ is proportional to the neutron concentration we finally get the reactor effect equation used in the computer model

$$
\frac{d Q_{1}}{d}=C_{1}\left(x_{1}-x_{0}\right) Q_{1}
$$

From (A4) the reactivity constant $C_{1}$ is estimated to $0.18 \sec ^{-1}$ setting $\lambda=0.08 \mathrm{sec}, \beta=0.075$ and $\rho=\rho$.m $=0.004$ for $x_{1}-x_{0}=0.5$. 


\section{B Two-phase mixture calculation}

For the pressurizer. steam generator and condenser, we have from (Lind.1992) the following two-fasc relation between total mass $M_{\mathrm{p}}$ total volume $V_{\mathrm{p}}$ water level $a$ and pressure $P$

$$
\begin{gathered}
M_{g}=V_{g}\left(\left(\rho_{g}(P)-P_{g}(P)\right) a+P_{g}(P)\right) \\
\left.U_{g}=V_{g}\left((\rho / P) h_{f}(P)-P_{g}(P) h_{g}(P)\right) a+P_{g}(P) h_{g}(P)\right)
\end{gathered}
$$

where $p_{p} h_{p} p_{g} h_{z}$ denote density and enthalphy of saturated resp. unsaturated water.

Defining

$$
\rho=\frac{M_{1}}{V_{1}} \quad \quad \quad \quad \quad \text { and } \quad \frac{U_{s}}{V_{1}}
$$

we get the relations

$$
\begin{gathered}
\rho=\left(\rho(P)-\rho_{g}(P)\right) \alpha+\rho_{g}(P) \\
u=\left(\rho(P) h_{d}(P)-\rho_{g}(P) h_{d}(P)\right) \alpha+\rho_{g}(P) h_{g}(P)
\end{gathered}
$$

By elimination of level $a$ we get

$$
\frac{\rho-\rho_{g}(P)}{u-\rho_{g}(P) h_{g}(P)}=\frac{\rho(P)-\rho_{g}(P)}{\rho(P) h(P)-\rho_{g}(P) h_{g}(P)}
$$

Defining the functions $\eta_{1}$ and $\eta_{2}$ by

$$
\begin{aligned}
& \eta_{l}(P)=\frac{\rho(P) h(P)-p_{f}(P) h_{f}(P)}{\rho(P)-P_{g}(P)} \\
& \nabla_{2}(P)=\frac{\rho_{(P)}(P)(P)\left(h(P)-h_{g}(P)\right)}{P_{f}(P)-P_{g}(P)}
\end{aligned}
$$


equation (B4) reduces to the cquation

$$
\rho \downarrow_{1}(P)+\nabla_{2}(P)=\boldsymbol{u}
$$

As the functions $\downarrow_{1}$ ind $\downarrow_{2}$ only depends on thermodynamic functions they are approximated by rational Chebyshev functions in the same way as the other steam and water functions used, thus saving computer time in solution of equation (B4).

Given mean density $\rho$ and volume specific energy $u$. the pressure $P$ is calculated from (B4) by a bisection algoritm (Lang,1980).

When pressure $P$ is calculated the relative water volume is ther, calculated from (BI) as

$$
\alpha=\frac{\rho-\rho_{g}(P)}{\rho_{f}(P)-\rho_{g}(P)}
$$

In the pressure range from 60 bar to 200 bar we have with an accuracy better than 1 per cent the second order apprximations

$$
\begin{aligned}
& \downarrow_{1}(P)=b_{21} P^{2}+b_{11} P+b_{01} \\
& \downarrow_{2}(P)=b_{22} P^{2}+b_{21} P+b_{02}
\end{aligned}
$$

and hence the equation (B4) can be solved explicit yjelding

$$
P_{\alpha 1}=\frac{\sqrt{\left(\rho b_{11}+b_{12}\right)^{2}-4\left(\rho b_{21}+b_{22}\right)\left(\rho b_{01}+b_{16}-u\right)}-\left(\rho b_{11}+b_{12}\right)}{2\left(\rho b_{21}+b_{22}\right)}
$$

The two-phase calculation is performed by the routine TWOFAS in the computer model. 


\section{Numerical integration strategy}

The numerical solution method chosen for the approximate integration of a system of first-order differential equations

$$
\frac{d y}{d}=\vec{\varepsilon}(\vec{v}, t)
$$

is the second order two point Runge-Kutta-Heun integration formula

$$
\vec{y}_{1}=\bar{y}_{0}+\frac{1}{2}\left(\vec{k}_{1}+\vec{k}_{2}\right)
$$

with

$$
\begin{aligned}
& \vec{k}_{1}=\overrightarrow{8}\left(\bar{y}_{0}, t_{0}\right) \Delta t \\
& \vec{k}_{2}=\overline{8}\left(\vec{y}_{0}+\vec{k}_{1}, t_{0}+\Delta t\right) \Delta t
\end{aligned}
$$

For the local per step approximation error vector we get

$$
\vec{E}=\vec{y}_{1}-\overrightarrow{y_{1}}\left(t_{1}\right) \quad-\frac{1}{2}\left(\vec{k}_{2}-\vec{k}_{1}\right)
$$

In the integration procedure we use an adaptive change of the integration step size $D T$ to ensure that at least local per step errors remain within specified bounds. Given the per step truncation error estimate vector coordinates $E^{(n)}, i=1, \cdots, n$ we halve or double $D T$ if the maximum relative fractional error

$$
\max _{1}\left|\frac{E^{(0)}}{\left|y_{1}^{(0)}\right|+\left|y_{1}^{(n)}-y_{0}^{(0)}\right|+1}\right|, i=1, \cdots, n
$$

falls outside an interval with upper bound EMAX and lower bound EMIN.

To avoid possible waste of computer time we also specify a minimum value DTMIN below which $D T$ is no longer halved. We also set an upper bound DTMAX, typically equal to the communication interval, i.e. the time interval between successive instants of process state variable estimations. 
Finally 10 avoid continuously halving or doubling of DT. the integration routines prevent DT from doubling if it was juse halved during the last sep and vice versa.

The values of EMAX. EP"IN. DTMAX. DTMIN and initial sening of DT is defined in the model input data file. 


\section{Thermodynamical approximations}

In the following tables a raional fenction

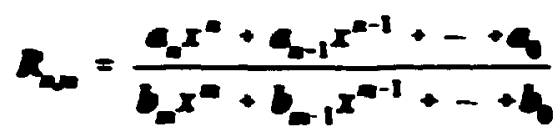

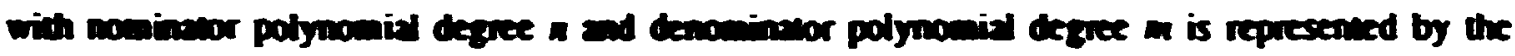
abureviation in motetion

$$
a_{a n}=\left[a a_{-10}-.0\right] /\left[b-b_{-10}-.4\right]
$$

All polynowials or rational fonctions are derived from Chebyster approximations (ref.[7]) and hence all anguments mast be transformed to the unit inderval [0.1] before calculation of the expressions.

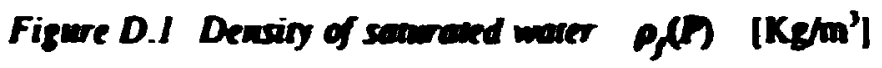

\begin{tabular}{l|l|l}
\hline $\begin{array}{c}\text { pressure } \\
\text { range (bar) }\end{array}$ & degree & \multicolumn{1}{|c}{ rational Chebyshev approximation } \\
\hline $0.01-0.2$ & 1,0 & {$[-8.320,990.0] /[1]$} \\
\hline $0.2-2.0$ & 2,0 & {$[6.975,-19.13,956.2] /[1]$} \\
\hline $2.0-200.0$ & 2,3 & {$[-262.4,266.3,765.5] /[-0.2095,0.6434,1.105]$} \\
\hline
\end{tabular}

Figure D.2 De:ising of sanurated skean $P_{g}(P) \quad\left[\mathrm{Kg} / \mathrm{m}^{3}\right]$

\begin{tabular}{l|c|c}
\hline $\begin{array}{c}\text { pressure } \\
\text { range (bar) }\end{array}$ & degree & \multicolumn{1}{c}{$\begin{array}{c}\text { rational Chebyshev } \\
\text { approximation }\end{array}$} \\
\hline $0.01-0.2$ & 2,1 & {$\left[2.142-10^{-2}, 8.681-10^{-2}, 7.004 \cdot 10^{-2}\right] /[0.3898,1.000]$} \\
\hline $0.2-2.0$ & 2,1 & {$[0.1385,0.6844,0.6341] /[0.3141,1.000]$} \\
\hline $2.0-110.0$ & 3,0 & {$[-0.3373,0.8430,3.272,29.02,28.06] /[1]$} \\
\hline $110-200$ & 3,0 & {$[2.575,4.629,9.500,45.30,98.62] /[1]$} \\
\hline
\end{tabular}


Figure D.3 Enthalpy of water (unsaturated) $h_{w}(T) \quad[\mathrm{MJ} / \mathrm{Kg}]$

\begin{tabular}{l|c|c}
\hline $\begin{array}{c}\text { temp. range } \\
(\circ \mathrm{C})\end{array}$ & degree & $\begin{array}{c}\text { ra.ional Chebyshev } \\
\text { approximation }\end{array}$ \\
\hline $10-350$ & 2,1 & {$\left[-0.4130,0.2205,7.267 \cdot 10^{-3}\right] /[-0.6481 .1 .000]$} \\
\hline
\end{tabular}

Figure D.4 Enthalpy of saturated water $h_{f}(P) \quad[\mathrm{M} / \mathrm{Kg}]$

\begin{tabular}{l|c|c}
\hline $\begin{array}{c}\text { pressure } \\
\text { range (bar) }\end{array}$ & degree & $\begin{array}{c}\text { ratiunal Chebyshev } \\
\text { approximation }\end{array}$ \\
\hline $0.01-0.2$ & 2,2 & {$\left[8.481 \cdot 10^{-2}, 0.2564,0.1751\right] /[0.1958,0.9725,0.9021]$} \\
\hline $0.2-2.0$ & 2,1 & {$\left[2.120 \cdot 10^{-2}, 0.3422,0.4268\right] /[0.5773,1.000]$} \\
\hline $2.0-200.0$ & 2,3 & {$[0.9973,2.139,1.143] /[-0.1097,0.3644,1.289,0.8178]$} \\
\hline
\end{tabular}

Figure D.5 Enthalpy of saturated steam $\left.h_{w}(I) \quad[\mathrm{M}] / \mathrm{Kg}\right]$

\begin{tabular}{l|c|c}
\hline $\begin{array}{c}\text { pressure } \\
\text { range (bar) }\end{array}$ & degree & \multicolumn{1}{c}{$\begin{array}{c}\text { rational Chebyshev } \\
\text { approximation }\end{array}$} \\
\hline $0.01-0.2$ & 2,0 & {$\left[-2.974 \cdot 10^{-2}, 4.203 \cdot 10^{-2}, 2.590\right] /[1]$} \\
\hline $0.2 \cdot 2.0$ & 2,0 & {$\left[-2.400 \cdot 10^{-2}, 4.400 \cdot 10^{-2}, 2.680\right] /[1]$} \\
\hline $2.0-200.0$ & 2,2 & {$[-1.338,1.592,3.290] /[-0.4132,0.6600,1.2067]$} \\
\hline
\end{tabular}

Figure D.6 Entropy of saturated water $\left.s_{f}(P) \quad, \mathrm{MJ} / \mathrm{Kg} / \circ \mathrm{C}\right]$

\begin{tabular}{|c|c|c|}
\hline $\begin{array}{l}\text { pressure } \\
\text { range (bar) }\end{array}$ & degree & $\begin{array}{l}\text { rational Chebyshev } \\
\text { approximation }\end{array}$ \\
\hline $0.01 \cdot 0.2$ & 2,2 & $\begin{array}{l}{\left[2.814 \cdot 10^{-4}, 8.573 \cdot 10^{-4}, 5.879 \cdot 10^{-4}\right] /[0.2086,0.9862 \text {, }} \\
0.8957]\end{array}$ \\
\hline $0.2 \cdot 2.0$ & 2,2 & {$\left[5.624 \cdot 10^{-5}, 1.053 \cdot 10^{-3}, 1.327 \cdot 10^{-3}\right] /[0.6019,1.000]$} \\
\hline $2.0-200.0$ & 2,2 & $\begin{array}{l}{\left[8.968 \cdot 10^{-4}, 3.957 \cdot 10^{-4}, 3.177 \cdot 10^{-3}\right] /[0.0996,0.9733 \text {, }} \\
0.9502]\end{array}$ \\
\hline
\end{tabular}


Figure D.7 Entropy of saturated steam $s_{8}(P) \quad\left[\mathrm{MJ} / \mathrm{Kg} /{ }^{\circ C}\right]$

\begin{tabular}{l|c|l}
\hline $\begin{array}{c}\text { pressure } \\
\text { range (bar) }\end{array}$ & degree & \multicolumn{1}{c}{$\begin{array}{c}\text { rational Chebyshev } \\
\text { approximation }\end{array}$} \\
\hline $0.01 \cdot 0.2$ & 1,1 & {$\left[4.924 \cdot 10^{-3}, 8.117 \cdot 10^{-3}\right] /[0.6436,1.000]$} \\
\hline $0.2-2.0$ & 1,1 & {$\left[3.578 \cdot 10^{-3}, 7.319 \cdot 10^{-3}\right] /[0.5266,1.000]$} \\
\hline $2.0 \cdot 200.0$ & 2,2 & $\begin{array}{l}{\left[-7.262 \cdot 10^{-4}, 4.387 \cdot 10^{-3}, 5.722 \cdot 10^{-3}\right] ;-3.38 \subseteq 6 \cdot 10^{-2}, 0.8974 .} \\
1.0170]\end{array}$ \\
\hline
\end{tabular}

Figure D.8 Temperature of saturated steam $\quad T_{g}(P) \quad[\mathrm{MJ} / \mathrm{Kg} / 0 \mathrm{C}]$

\begin{tabular}{l|c|c}
\hline $\begin{array}{c}\text { pressure } \\
\text { range (bar) }\end{array}$ & degree & \multicolumn{1}{c}{$\begin{array}{c}\text { rational Chebyshev } \\
\text { approximation }\end{array}$} \\
\hline $0.01-0.2$ & 2,2 & {$[19.95,61.05,41.97] /[0.1914,0.9664,0.9043]$} \\
\hline $0.2-2.0$ & 2,2 & {$[23.43,104.72,95.83] /[0.1164,0.8145,0.9418]$} \\
\hline $2.0-200.0$ & 2,2 & {$[143.3,405.1,266.7] /[0.2833,1.101,0.8584]$} \\
\hline
\end{tabular}

Figure D.9 Water density gradient $\frac{d}{d t} \rho_{w}(I) \quad\left[\mathrm{Kg} / \mathrm{m}^{3} / \mathrm{oC}\right]$

\begin{tabular}{c|c|c}
\hline $\begin{array}{c}\text { temp range } \\
(\circ \mathrm{C})\end{array}$ & degree & $\begin{array}{c}\text { rational Chebyshev } \\
\text { approximation }\end{array}$ \\
\hline $150-360$ & 3,2 & {$[0.2048,0.3806,-0.3059,-1.787) /[-0.3589,-0.5416,1.180]$} \\
\hline
\end{tabular}




\section{E Power plant process variables}

Table 5 - Process state variables

\begin{tabular}{ll}
\hline Q1 & reactor nuclear effect [MW] \\
UT1 & reactor energy [MJ] \\
UT2 & steam generator tube side energy $[\mathrm{MJ}]$ \\
UT3 & steam generator shell side energy [MJ] \\
M3 & steam generator shell side mass [Kg] \\
UT5 & condenser energy [MJ] \\
M5 & condenser mass [Kg] \\
UT7 & pressurizer energy $[M J]$ \\
M7 & pressurizer mass [Kg] \\
M8 & volume control tank mass [Kg] \\
Z30 & steam gen. level ctrl. reset signal [RPM] \\
Z31 & steam gen. press ctr. reset signal $[M W]$ \\
Z32 & power controller reset signal [0,1] \\
Z33 & pressurizer level ctrl. reset signal $[-1,1]$ \\
Z34 & pressurizer press ctr. reset signal $[-1,1]$ \\
CO3 & steam generator activity concentration $[0,1]$ \\
CO5 & condenser activity concentration $[0,1]$ \\
EM6 & turbine generator kinetic energy $[M J]$ \\
X1 & reactor control rod position $[0,1]$ \\
& \\
\hline
\end{tabular}

Table 6. Process paramerers

$\begin{array}{ll}\text { DP10 } & \text { steam generator safety valve pressure setpoint [bar] } \\ \text { DP15 } & \text { pressurizer safety valve pressure setpoint [bar] } \\ \text { REF1 } & \text { control rod setpoint }[0,1] \\ \text { REF30 } & \text { steam generator level controller setpoint }[0,1] \\ \text { REF31 } & \text { steam generatur pressure controller setpoint [bar] } \\ \text { REF32 } & \text { power coiritiller sctpoint }[Y] \\ \text { REF33 } & \text { pressurizer level setpoint }[0,1] \\ \text { REF34 } & \text { pressurizer pressure setpoint [bar] } \\ \text { CTL1 } & \text { reactor trip status }[0,1] \\ \text { CTL6 } & \text { turbine/generator trip status }[0,1] \\ \text { CTL7 } & \text { pressurizer heater auto/manual status }[0,1] \\ \text { CTL11 } & \text { turbine valve auto/manual status }[0,1] \\ \text { CTL12 } & \text { turbine bypass valve auto/manual status }[0,1] \\ \text { CTL13 } & \text { pressurizer spray control valve auto/manual status }[0,1] \\ \text { CTL14 } & \text { volum control valve auto/manual status }[0,1] \\ \text { CTL20 } & \text { reactor cooling pump auto/manual status }[0,1] \\ \text { CTL21 } & \text { teedwater pump auto/manual status }[0,1] \\ \text { CTL22 } & \text { cooling water pump auto/manual status }[0,1] \\ \text { CTL23 } & \text { volume control pump auto/manual status }[0,1] \\ \text { CTL30 } & \text { steam generator level controller auto/manual status }[0,1]\end{array}$


Table 6. Process parameters (continued)

CTL31

CTL32

CTL33

CTL34

CTL35

ERR1

ERR6

ERR7

ERR10

ERR11

ERR12

ERR13

ERR14

ERR15

ERR20

ERR21

ERR22

ERR23

ERR30

ERR31

ERR32

ERR33

ERR34

ERR35

ERR24

ERR25 steam generator pressure controller auto/manual status $[0,1]$ turbine power controller auto/manual status $[0,1]$

pressurizer level controller auto/manual status $[0,2]$ pressurizer pressure controller auto/manual status $[0,2]$ reactor control rod drive auto/manual status $[0,2]$ reactor control rod error status $[-1,1]$ turbine/generator onvoff error flag $[-1,1]$ pressurizer heater power onoff error flag $[-1,1]$ steam generator safety valve error status $[-1,1]$ turbine valve error status $[-1,1]$ turbine bypass valve error status $[-1,1]$ preisurizer spray valve entor status $[-1,1]$ volume control value error status $[-1,1]$ pressurizer safety valve error status $[-1,1]$ reactor cooling pump power error status $[-1,1]$ feedwater pump power error status $[-1,1]$ cooling water pump power error status $[-1,1]$ volume control pump power error status $[-1,1]$ steam generator level controller error status $[-1,1]$ steam generator pressure controller error status $[-1,1]$ turbine power controller error status $[-1,1]$ pressurizer level controller error status $[0,2]$ pressurizer pressure controller error status $[0,2]$ reactor control rod drive enror status $[0,2]$ reactor cooling system oil pump power status $[-1,1]$ feedwater system oil pump pover status $[-1,1]$ 


\begin{tabular}{|c|c|}
\hline $\begin{array}{l}\text { P1 } \\
\text { P2 } \\
\text { P3 } \\
\text { P5 } \\
\text { P7 } \\
\text { P8 } \\
\text { P11 } \\
\text { DP11 } \\
\text { T1 } \\
\text { T2 } \\
\text { T3 } \\
\text { T4 } \\
\text { T5 } \\
\text { T7 } \\
\text { T24 } \\
\text { T25 } \\
\text { T8 } \\
\text { T9 } \\
\text { U1 } \\
\text { U2 } \\
\text { U3 } \\
\text { U4 } \\
\text { U5 } \\
\text { U6 } \\
\text { U7 } \\
\text { U9 } \\
\text { F1 } \\
\text { F2 } \\
\text { F3 } \\
\text { F4 } \\
\text { F5 } \\
\text { F6 } \\
\text { F7 } \\
\text { F8 } \\
\text { F9 } \\
\text { F10 } \\
\text { F12 } \\
\text { F13 } \\
\text { F14 } \\
\text { F15 } \\
\text { F16 } \\
\text { F24 } \\
\text { FLK2 } \\
\text { W1 } \\
\text { X11 } \\
\text { X12 } \\
\text { X13 } \\
\text { X14 }\end{array}$ & 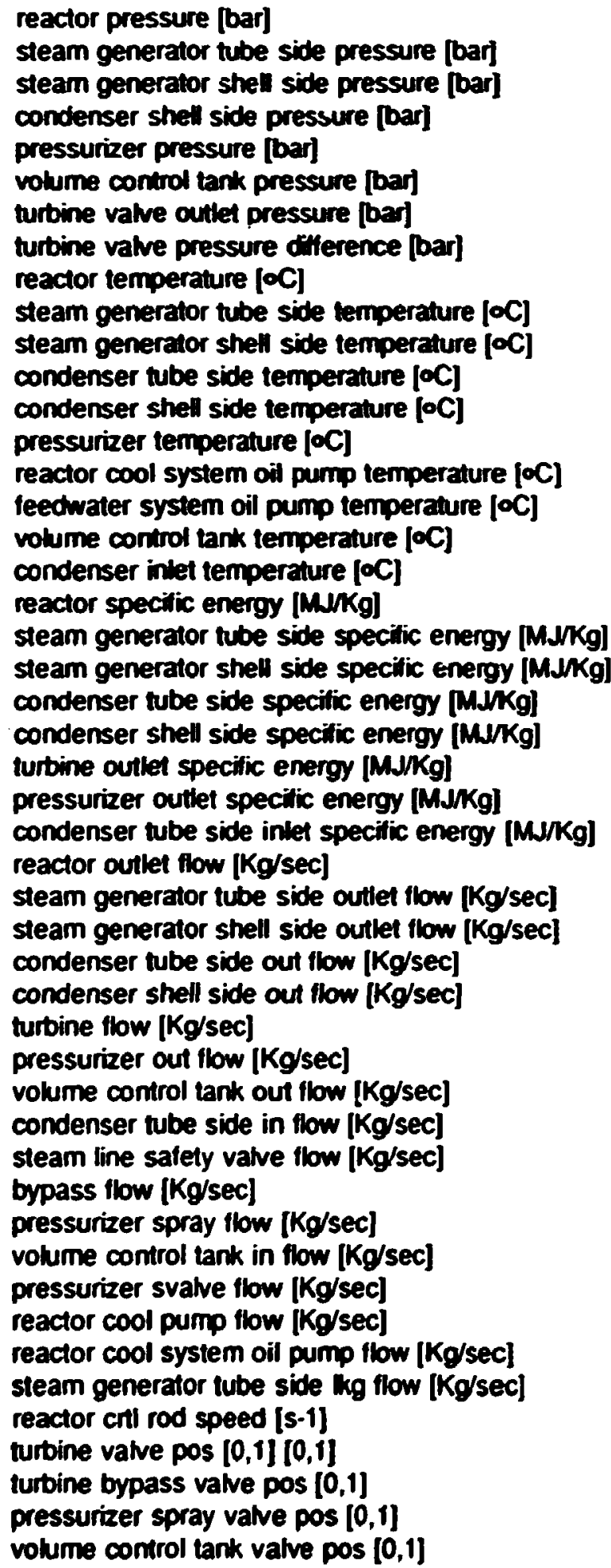 \\
\hline
\end{tabular}




\begin{tabular}{|c|c|}
\hline $\begin{array}{l}\text { AC3 } \\
\text { AC5 } \\
\text { AC6 } \\
\text { AC10 } \\
\text { AC12 } \\
\text { E7 } \\
\text { O7 } \\
\text { O23 } \\
\text { O45 } \\
\text { ALA3 } \\
\text { ALFA5 } \\
\text { A.FA7 } \\
\text { ALAB } \\
\text { C11 } \\
\text { C12 } \\
\text { C13 } \\
\text { C14 } \\
\text { OM20 } \\
\text { OM21 } \\
\text { OM22 } \\
\text { OM23 } \\
\text { OM24 } \\
\text { OM6 } \\
\text { A6 } \\
\text { V6 } \\
\text { W6 } \\
\text { WE6 } \\
\text { OR1 }\end{array}$ & 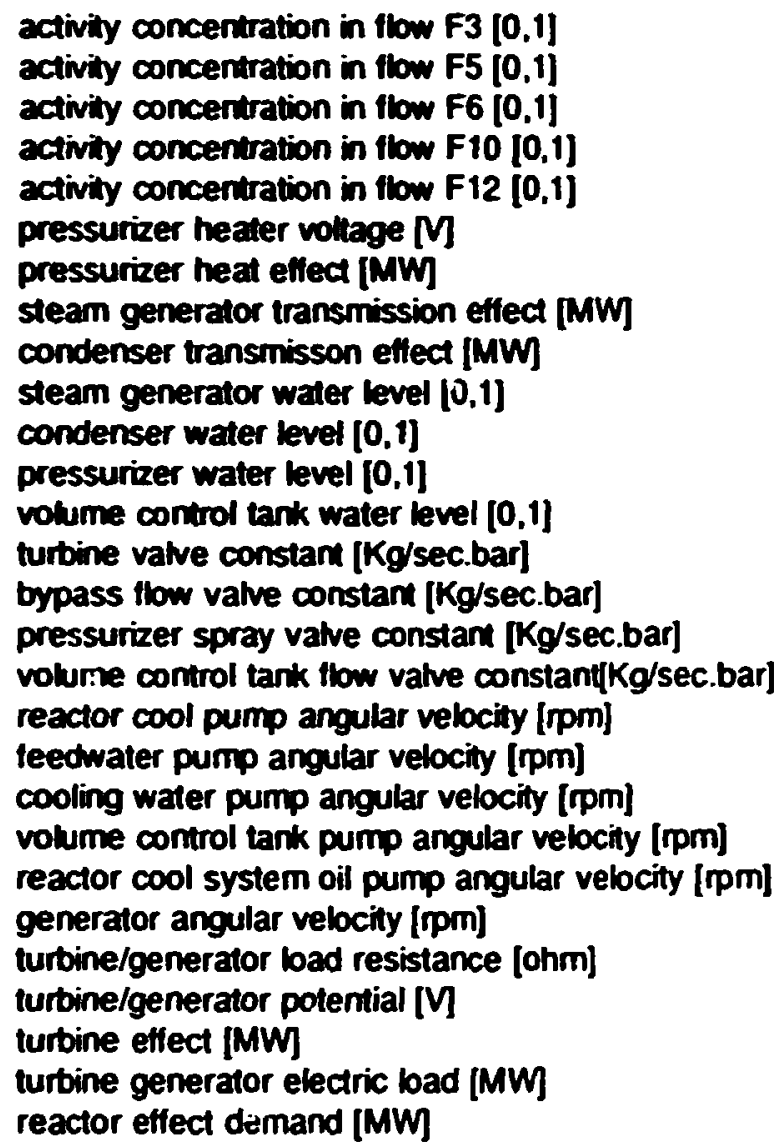 \\
\hline
\end{tabular}




\begin{tabular}{|c|c|}
\hline $\begin{array}{l}\text { C1 } \\
\text { M1 } \\
\text { V1 } \\
\text { M2 } \\
\text { V2 } \\
\text { R1 } \\
\text { R2 } \\
\text { '3 } \\
\text { V5 } \\
\text { V7 } \\
\text { R7 } \\
\text { V8 } \\
\text { C10 } \\
\text { C15 } \\
\text { CT6 } \\
\text { K23 } \\
\text { K45 } \\
\text { QQ30 } \\
\text { T130 } \\
\text { QO31 } \\
\text { T131 } \\
\text { QO32 } \\
\text { T132 } \\
\text { QO33 } \\
\text { T132 } \\
\text { C33 } \\
\text { QQ34 } \\
\text { T134 } \\
\text { C34 } \\
\text { C20 } \\
\text { R20 } \\
\text { C21 } \\
\text { R21 } \\
\text { C22 } \\
\text { R22 } \\
\text { DP22 } \\
\text { C23 } \\
\text { R23 } \\
\text { GM16 } \\
\text { CG6 } \\
\text { OMAX6 } \\
\text { H1 } \\
\text { H2 } \\
\text { CLK2 } \\
\text { OQ35 } \\
\text { C35 }\end{array}$ & 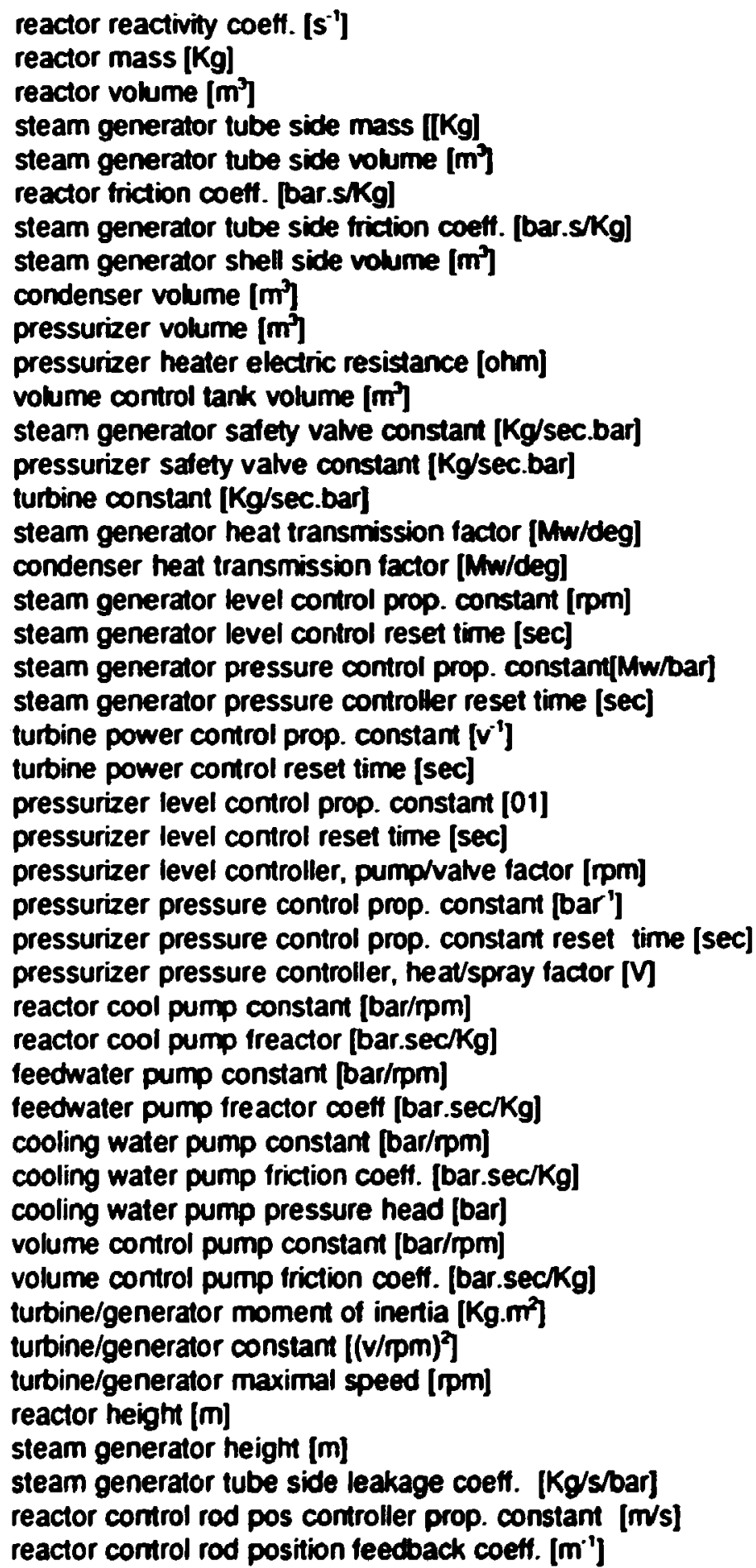 \\
\hline
\end{tabular}


WMAX1 reactor control rod maximal speed [s-']

OMNX20 reactor cool pump maximal angular velocity [pm]

OMAX21 teedwater pump maximal angular velocily [pm]

OMAX22 cooling weter pump maximal angular velociny [pm]

OMNX23 volume control purnp maximal angular velociny [pm]

EMAX7 pressurizer hezter maximal voliage M]

WEMAX6 tubinedgenerabr maxinal bad [Miw]

OMNX24

OMA 25

C24

C25

A17

reactor cool system oil pump maximal velociny [mm] feedweker system oil pump maximal velocity [pm] reactor cool system oil pump constan [Dat/pm] feedwater system oil pump constant [bar/ipm] reactor cool system oif finer constant [bar.sec/Kg]

R18 feedwater system oil filler constant (bar.seckK)

A19 cooling water finer constant [bor.sec/Kg] 


\section{F Model steady state input data}

A data input file containing steady state process variable data testing the model in ecivilibrium is listed below. It contains labelled blocks of initial values for all process variables used for est of the model.

The labels have the following interpretation:

IDENT Data identification.

DT Initial value for internal adaptive integration step length.

TMux Maxinal process time and communication interval (table step length).

ERROR Limits for relative integration enor and limils for adaplive DT.

IC

Initial values tor process state variables.

PARAM Process parameter values.

CONST Process constant values.

VAR Initial vahes for proress variables.

Data file content.

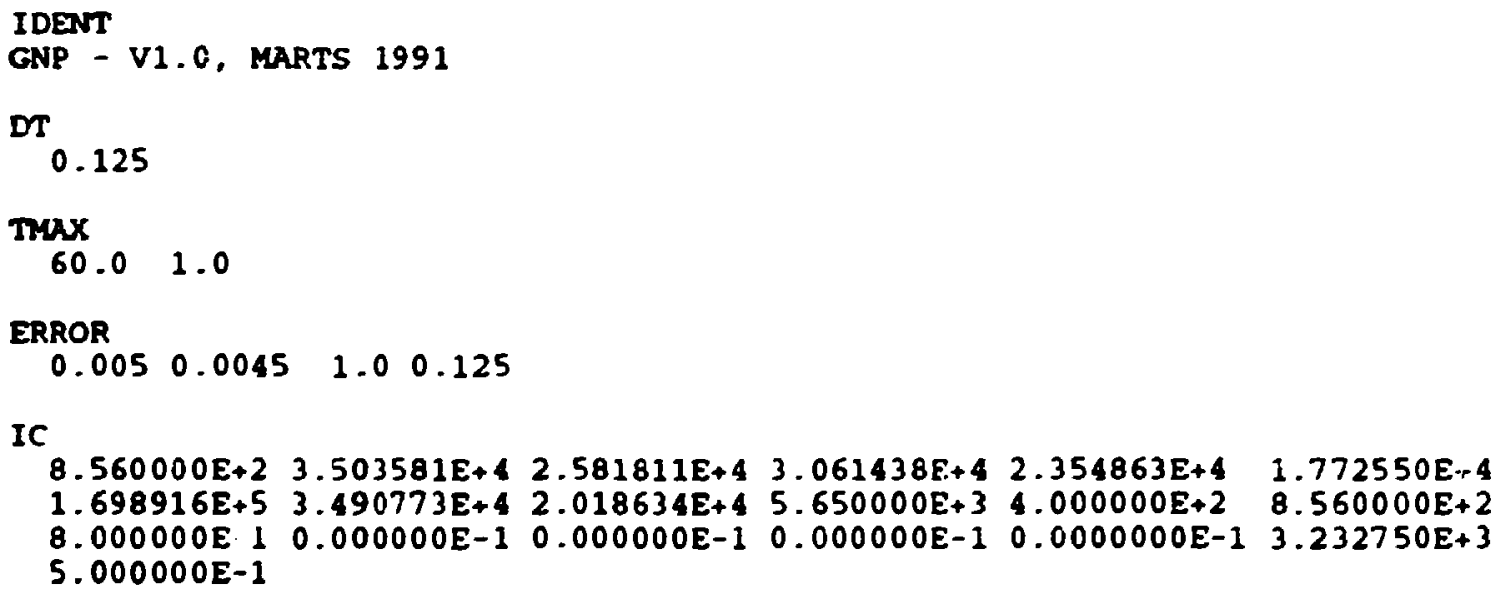

$\begin{array}{rrrrrr}80.0 & 174.0 & 0.50 & 0.50 & 65.00 & 30.00 \\ 0.60 & 158.0 & -1.00 & -1.00 & -1.00 & -1.00 \\ -1.00 & -1.00 & -1.00 & -1.00 & -1.00 & -1.00 \\ -1.00 & -1.00 & -1.00 & -1.00 & -1.00 & -1.00 \\ -1.00 & -1.00 & -1.00 & -1.00 & -1.00 & -1.00 \\ -1.00 & -1.00 & -1.00 & -1.00 & -1.00 & -1.00 \\ -1.00 & -1.00 & -1.00 & -1.00 & -1.00 & -1.00\end{array}$


CONST

$\begin{array}{llllll}1.800000 E-1 & 2.308003 E+4 & 3.500000 E+1 & 1.986508 E+4 & 2.720000 E+1 & 8.417356 E-4 \\ 6.376785 E-4 & 6.0000 E+1 & 4.260000 E+2 & 5.00000 E+1 & 5.0000 E+1 & 1.130000 E+1\end{array}$

$6.376785 E-4$ 6.0000E+1

$2.153846 \quad 1.005063$

$1.210000 E+29.650000$

6.158181

$1.236466 E+21.090749 E+25.260000 E+2$

$1.750000 E+2 \quad 1.180000 E+3 \quad 7.400000 E-2 \quad 1.560000 E+2 \quad 1.070000 E+2 \quad 1.945151 E-2$

$1.479414 \mathrm{E}-3 \quad 3.248400 \mathrm{E}-1 \quad 2.030070 \mathrm{E}-1 \quad 1.666667 \mathrm{E}-3 \quad 1.964650 \mathrm{E}-5 \quad 1.0000$

$3.437778 \mathrm{E}-1 \quad 2.812727 \mathrm{E}+1 \quad 1.810000 \mathrm{E}+5 \quad 2.519526 \mathrm{E}-2 \quad 3.0000 \mathrm{E}+3 \quad 2.0000$

$\begin{array}{llllll}5.0000 & 0.0000 & 6.200000 E-3 & 9.340000 & 1.0000 E-2 & 6.0000 E+2\end{array}$

$6.0000 E+2 \quad 6.0000 E+2 \quad 1.800000 E+3 \quad 9.500000 E+3 \quad 5.0000 E+2 \quad 1.800000 E+3$

$1.800000 E+31.111111 E-41.111111 E-42.0000 E+1 \quad 2.0000 E+1 \quad 1.964650 E-5$

VAR

$1.613000 \mathrm{E}+2 \quad 1.555000 \mathrm{E}+2 \quad 6.500000 \mathrm{E}+1 \quad 3.200000 \mathrm{E}-2 \quad 1.580000 \mathrm{E}+2 \quad 1.100000$

$5.200000 E+1 \quad 1.300000 E+1 \quad 3.300000 E+2 \quad 2.930000 E+22.791541 E+22.0000 E+1$

$2.488441 E+1 \quad 3.451295 E+2 \quad 1.500000 E+1 \quad 1.500000 E+1 \quad 1.518014 \quad 1.299673$

$\begin{array}{llllll}2.779013 & 1.227360 & 1.042505 E-1 & 1.768998 & 1.629765 & 1.206427\end{array}$

$3.920471 E+3 \quad 3.920471 E+3 \quad 3.200284 E+2 \quad 2.544983 E+4 \quad 3.200284 E+2 \quad 3.200284 E+2$

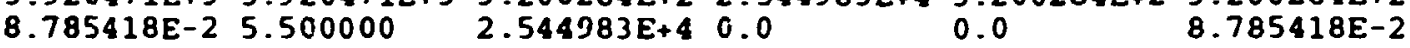

$\begin{array}{llllll}5.500000 & 0.0 & 3.920471 E+3 & 0.0 & 0.0 & 8.0000 E-1\end{array}$

$0.0 \quad 1.520000 E-3 \quad 5.0000 E-1 \quad 0.0$

$\begin{array}{ll}0.0 & 8.000 \\ 0.0 & 0.0\end{array}$

0.0

204159

2. $900000 \mathrm{E}-2$

5.0000E-1

$4.0000 \mathrm{E}-1 \quad 6.0000 \mathrm{E}-1$

$560000 \mathrm{E}+2$

$1.751479 E+1 \quad 6.962025 E-2$

$1.890000 E+2 \quad 2.784363$

6.0000

5. $0000 E-1$

$3.077196 \mathrm{E}+1 \quad 4.925938$

$1.800000 \mathrm{E}+3 \quad 1.0000 \mathrm{E}-2$

$3.0000 E+1$

$9.00 \cap 0 E+2$

$6.045454 E+11.800000 E+31.0000 E-2$ 
Titk and mothor(s)

Simulation of a PWR Power Plant for Process

Control and Diagnosis

Finn Ravnsbjerg Nielsen

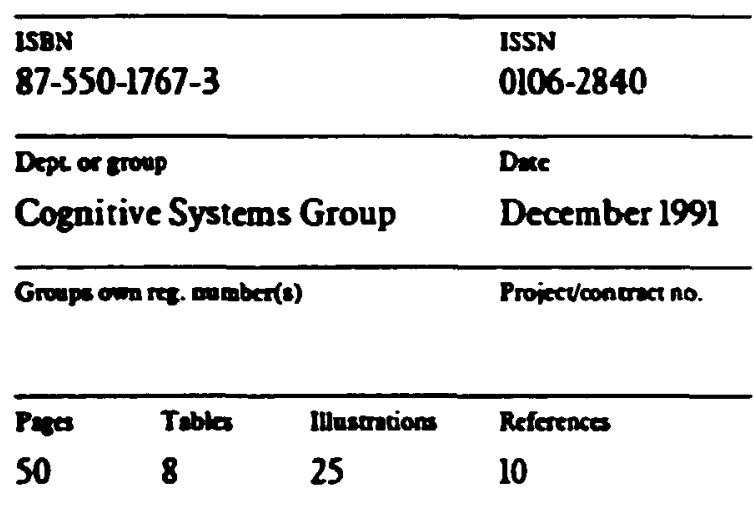

Aberact (Minx. 2000 charactas)

A computer model of a simplified pressurized nuclear power plant is developed with aim at studies concerning process control, diagnosis and decision making.

The model includes the traditional PWR plant components, primary circuit with reactor, pressurizer and steam generator, steam circuit with steam line, turbine and condenser, interconnected with pumps, valves and controllers. The model can be used for calculation of unansients for both normal operation and incidents such as turbine trip, loss of feedwater, run lown of pumps or various valve failures.

The computer model is not directed to any specific existing plant. For convenience and alleviation in implementation the physical description of many components are simplified to an extent where the qualitative behavior of the system is not violated. For computer memory economy a variety of thermodynamical functions for water and steam have been approximated with analytical expressions based on table values.

The model is implemented in the $\mathrm{C}$ language and bas been run on both the IBM PC and the SUN workstation.

Dearipron WIS/EDB

COMPUTERIZED SIMULATION; MATHEMATICAL MODELS; PWR TYPE REACTORS; REACTOR CONTROL SYSTEMS; REACTOR OPERATION

Avibble ca requen tom Ris Library, Ris Nuional Loboneory, (Ris Bibliond, For'mingoenter Rive), P.O.Bon 49,

DK 4000 Reckilde, Dennerk.

Telophose + 4\$ 423712 12, ex. 2262/2269

Tdex 43116 . Tdefix + 4546755627 . 
Available on request from:

Risø Library

Risø National Laboratory,

P.O. Box 49, DK-4000 Roskilde, Denmark

Phone + 45423712 12, ext. 2268/2269

ISBN 87-550-1767-3

Telex 43116, Telefax +4546755627

ISSN 0106-2840 